\title{
Cancer intelligence acquired (CIA): tumor glycosylation and sialylation codes dismantling antitumor defense
}

\author{
Kayluz Frias Boligan • Circe Mesa • \\ Luis Enrique Fernandez $\cdot$ Stephan von Gunten
}

Received: 30 September 2014/Revised: 27 November 2014/ Accepted: 1 December 2014/Published online: 7 December 2014

(C) Springer Basel 2014

\begin{abstract}
Aberrant glycosylation is a key feature of malignant transformation and reflects epigenetic and genetic anomalies among the multitude of molecules involved in glycan biosynthesis. Although glycan biosynthesis is not template bound, altered tumor glycosylation is not random, but associated with common glycosylation patterns. Evidence suggests that acquisition of distinct glycosylation patterns evolves from a 'microevolutionary' process conferring advantages in terms of tumor growth, tumor dissemination, and immune escape. Such glycosylation modifications also involve xeno- and hypersialylation. Xeno-autoantigens such as Neu5Gc-gangliosides provide potential targets for immunotherapy. Hypersialylation may display 'enhanced self' to escape immunosurveillance and involves several not mutually exclusive inhibitory pathways that all rely on protein-glycan interactions. A better understanding of tumor 'glycan codes' as deciphered by
\end{abstract}

K. F. Boligan · S. von Gunten $(\varangle)$

Institute of Pharmacology, University of Bern,

Friedbühlstrasse 49, 3010 Bern, Switzerland

e-mail: stephan.vongunten@pki.unibe.ch

K. F. Boligan

e-mail: kayluz.frias@pki.unibe.ch

C. Mesa

Immunobiology Division, Center of Molecular Immunology,

216 St and 15th Ave., Atabey, Playa, P.O. Box 16040,

11600 Havana, Cuba

e-mail: circe@cim.sld.cu

L. E. Fernandez

Innovation Division, Center of Molecular Immunology,

216 St and 15th Ave., Atabey, Playa, P.O. Box 16040,

11600 Havana, Cuba

e-mail: luis@cim.sld.cu lectins, such as siglecs, selectins, C-type lectins and galectins, may lead to novel treatment strategies, not only in cancer, but also in autoimmune disease or transplantation.

Keywords Xeno-autosialylation - Cancer glycosylation Cancer immunoediting - Sialoglycans · Altered branching . Tumor immunosuppression

\begin{tabular}{|c|c|}
\hline \multicolumn{2}{|c|}{ Abbreviations } \\
\hline $\mathrm{C} 2 \mathrm{GnT}$ & $\begin{array}{l}\text { Core } 2 \beta 1,6-N- \\
\text { acetylglucosaminyltransferase }\end{array}$ \\
\hline CEACAM-1 & CEA-related cell adhesion molecule- 1 \\
\hline CLR & C-type lectin receptors \\
\hline CRD & Carbohydrate-recognition domains \\
\hline DTDST & Diastrophic dysplasia sulfate transporter \\
\hline FUT & Fucosyltransferase \\
\hline ITIM & $\begin{array}{l}\text { Immunoreceptor tyrosine-based inhibition } \\
\text { motif }\end{array}$ \\
\hline $\mathrm{LOH}$ & Loss of heterozygosity \\
\hline MGAT3 & $\begin{array}{l}\text { Mannosyl (beta-1,4-)-glycoprotein beta- } \\
1,4-N \text {-acetylglucosaminyltransferase }\end{array}$ \\
\hline MGAT5 & $\begin{array}{l}\text { Mannosyl (alpha-1,6-)-glycoprotein beta- } \\
1,6-N \text {-acetylglucosaminyltransferase }\end{array}$ \\
\hline MICA & MHC class I-related chain A \\
\hline NGcGM3 & $N$-Glycolyl GM3 ganglioside \\
\hline NAcGM3 & $N$-Acetyl GM3 ganglioside \\
\hline NSCLC & Non-small cell lung cancer \\
\hline ppGalNAcT & Polypeptide $N$-acetylgalactosyl transferase \\
\hline PSGL-1 & P-selectin glycoprotein ligand-1 \\
\hline SAMPs & Self-associated molecular patterns \\
\hline Siglec & $\begin{array}{l}\text { Sialic acid-binding immunoglobulin-like } \\
\text { lectin }\end{array}$ \\
\hline sT & Sialyl-T antigen \\
\hline ST6Gal 1 & Beta-galactoside $\alpha$-2,6-sialyltransferase 1 \\
\hline sTn & Sialyl-Tn antigen \\
\hline
\end{tabular}


T Thomsen-Friedenreich

TACA Tumor-associated carbohydrate antigen

VSSP Very small-sized proteoliposomes

\section{Introduction}

The "glycome" has been defined as the complete set of glycans and glycoconjugates (covalent complexes with proteins or lipids) that are made by a cell or organism under specific conditions [1]. The glycome depends on biosynthetic pathways that involve the concerted action of glycosyltransferases, glycosidases and other glycan-modifying enzymes that are encoded by $250-500$ glycogenes representing 1-2\% of the total human genome [2]. Despite the conservation of glycogenes, major intra- and interspecies variations of the glycome exist [3, 4], whereby glycosylation patterns are often tissue- or cell lineagespecific [5, 6]. Thus, glycan biosynthesis represents an organized, highly regulated process, even if the generation of glycans, unlike proteins, does not rely on a templatebased mechanism, but instead on a machinery of different enzymes that elongate, branch or trim a specific substrate. By its complex nature, involving multiple players, glycan biosynthesis is particularly sensitive to epigenetic and environmental factors (Fig. 1). Yet, given the involvement of glycans in myriad biological processes, tight control of glycan biosynthesis and repertoire is required to maintain tissue homeostasis and health [7]. An altered cellular glycosylation profile is not only indicative for a pathological process, but may have functional consequences, and influence the pathogenesis or progression of disease, including cancer. Indeed, aberrant glycosylation is a characteristic feature of carcinogenesis that influences tumor immunity, angiogenesis and multiple steps of tumor progression, such as tumor growth and proliferation, migration, invasion, and metastasis $[8,9]$.

As a further biochemical dimension to nucleic acids and proteins [10], the glycome encodes biological information, which is deciphered by glycan-binding proteins (lectins) and antibodies [11, 12]. Glycan-binding proteins include membrane-associated molecules, such as selectins, siglecs and most C-type lectins, or soluble proteins such as galectins. Latter are evolutionary highly conserved [13], and by means of carbohydrate-recognition domains (CRDs) that recognize $\beta$-galactose, they are able to establish bivalent or multivalent cell-cell and cell-matrix interactions, and to crosslink transmembrane proteins, eventually resulting in a cascade of transmembrane signaling events [14]. The bi- or multivalency of galectins involves the formation of dimers ("prototype" galectins; Galectin- $1,-2,-5,-7,-10,-11,-13,-14$, and -15$)$, the linkage of two CRDs in tandem by a single polypeptide chain ("tandem-repeat" galectins; Galectin-4, -6, -8, -9, and -12), or oligomerization induced by a non-lectin $\mathrm{N}$-terminal region (Galectin-3). In analogy to lattices formed by antibodies and multivalent antigens, galectins can form ordered arrays of complexes [14], and may confer innate antibody-like immunity [11].

Several glycoconjugates constitute danger-associated molecular patterns (DAMPs; e.g. hyaluronan fragments, certain proteoglycans) or pathogen-associated molecular patterns (PAMPs; e.g. lipo-oligosaccharides, peptidoglycans). Other glycans, including sialic acid-containing glycans (sialoglycans), which are dominant on cells of the deuterostome lineage of animals [15] and are recognized by intrinsic inhibitory receptors of immune cells, could be regarded as 'self-associated molecular patterns (SAMPs)' [16]. Indeed, hypersialylation of cancer cells may display 'enhanced self' or 'super-self' to exploit natural inhibitory pathways for immune evasion [17].

Interestingly, certain glycosylation phenotypes occur more frequently in cancer than others (Fig. 1), suggesting that these changes reflect the outcome of 'Darwinian selection' [9] in terms of the capacity to grow, disseminate, and to cope up with diverse microenvironmental and immunological survival pressure. Glycan-binding proteins, as sensors of glycosylation patterns, play a key role in these processes. We discuss common tumorassociated glycosylation patterns and highlight the concept that acquired epigenetic or genetic alterations of the glycosylation code displayed by cancer cells, may engage or deafen different protein-glycan sensor systems to misinform and subvert actions of the immune system. A special focus of this article is on recent insights related to tumor-associated modifications of the sialome, which are among the most prominent features of altered tumor glycosylation.

\section{Tumor glycosylation and sialylation patterns}

Essentially all tumor cells exhibit altered carbohydrate composition and structure compared to their progenitors, and distinct glycosylation patterns have been associated with oncogenic transformation, which may result from altered glycan biosynthesis, neosynthesis of onco-fetal antigens or organizational changes in density or crypticity at surfaces [18]. Furthermore, certain glycoproteins and lipids, such as mucins and gangliosides, are overproduced by cancer cells, and are eventually secreted or 'shed' as soluble glycoconjugates [19-22]. Indeed, most serum markers currently in use are glycoconjugates that harbor tumor-associated carbohydrate antigens (TACA) [23]. Common cancer glycans include sialyl Lewis $\mathrm{x}\left(\mathrm{sLe}^{\mathrm{x}}\right)$, 


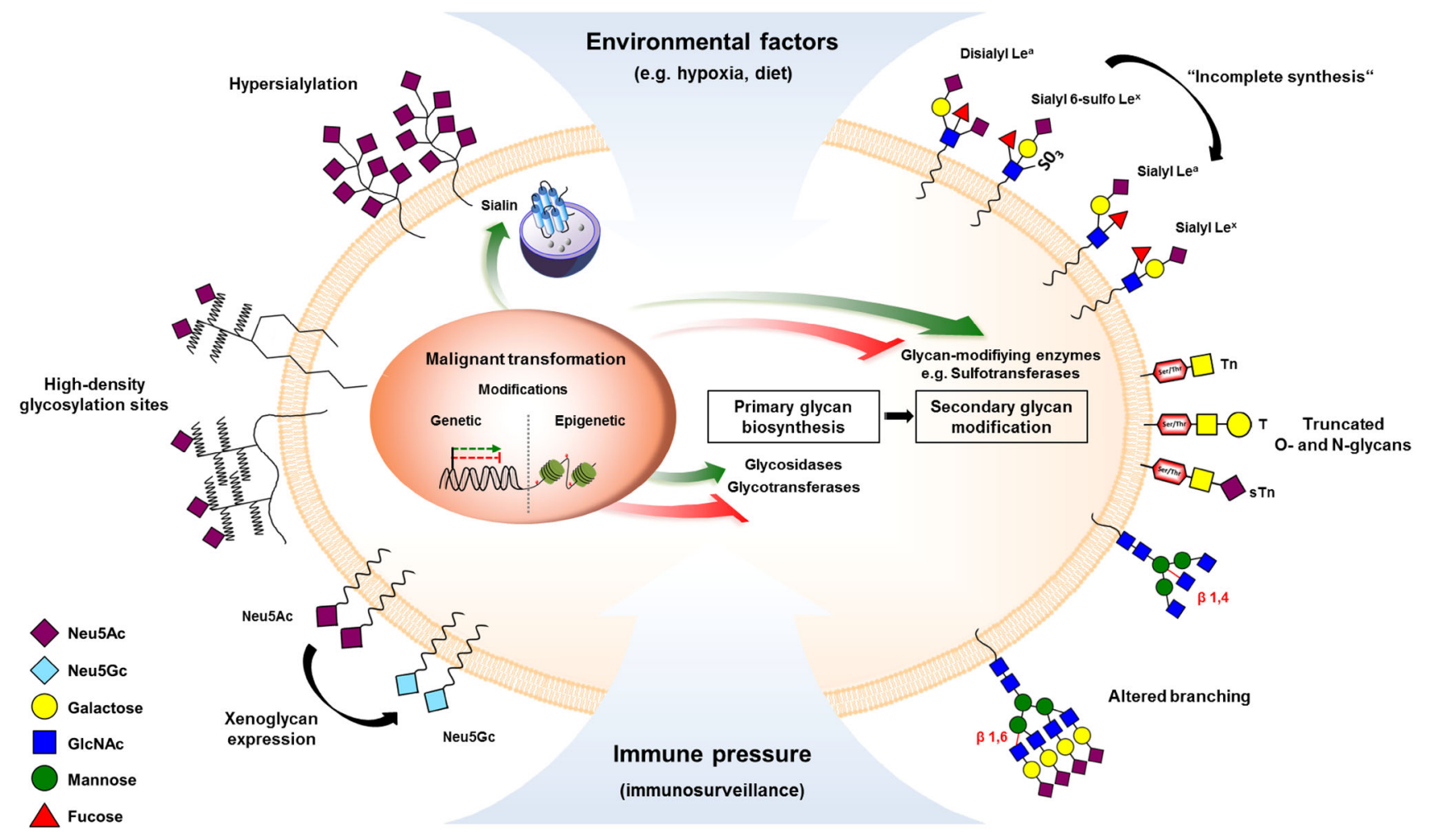

Fig. 1 Characteristic patterns of tumor surface glycosylation as a consequence of epigenetically and genetically modified glycan biosynthesis. Glycan synthesis is not template bound but involves the concerted action of glycosyltransferases, glycosidases and glycanmodifying enzymes (e.g. sulfotransferases). The glycan machinery is frequently modified upon malignant transformation due to epigenetic

sialyl Lewis a (sLe $\left.{ }^{\mathrm{a}}\right)$, sialyl Tn (sTn), Thomsen-Friedenreich $(\mathrm{T})$, Lewis y $\left(\mathrm{Le}^{\mathrm{y}}\right)$, Globo $\mathrm{H}$, polisialic acid (PSA), GD2, GD3, fucosyl GM1, GM2 [19]. Advantages of glycan antigens may be that unlike proteins a glycan is not a direct product of genes, and may reflect multiple genetic and epigenetic anomalies and even genetic silencing (incomplete synthesis).

Glycans range from highly branched and complex structures (e.g. $N$-linked and $O$-linked glycans, and glycolipids) to linear glycans (e.g. proteoglycans). They include $N$-glycans, $O$-glycans, and glycolipids, and are typically composed of a central core, which is constitutive in most cell types, an intermediate backbone (e.g. repeating poly- $N$-acetyllactosamine units), and subultimate and terminal sugars at 'outer' positions [6]. The biosynthesis of $N$-linked glycans involves the en bloc transfer of a common 14-sugar glycan to an asparagine residue of a protein that is being synthesized and translocated through the endoplasmatic reticulum (ER) membrane, and the subsequent enzymatic remodeling of the glycan structure in the ER and Golgi [24]. $O$-linked glycans are attached to serine (Ser) or threonine (Thr) and genetic changes. Environmental factors and immune pressure may lead to characteristic tumor-associated cell surface glycosylation patterns (see main text), including hypersialylation, truncation, altered branching, and even xenoglycosylation, which may confer a survival advantage to face the diverse challenges imposed by the host

residues of a carrier protein, whereby the addition of an $\mathrm{N}$-acetylgalactosamine to the Ser or Thr is mediated by a polypeptide $N$-acetylgalactosyl transferase (ppGalNAcT), of which at least twelve isoforms are present in mammals. $O$-linked glycans are very heterogeneous, with up to eight different core structures (Core 1-8) [6, 25]. $O$-linked glycans have been found to be relevant to mucin structure and to determine their functions in tumor progression, including cellular growth, differentiation, invasion and immune surveillance (reviewed in [20, 22]).

Sialic acids are a family of nine-carbon backbone monosaccharides that are typically found at the outermost end of glycoconjugates, including $N$-acetylneuraminic acid (Neu5Ac) and the non-human $N$-glycolylneuraminic acid (Neu5Gc), which are the most common sialic acid structures found on mammalian cells [26]. Sialic acidcontaining carbohydrate structures (sialoglycans) and other terminal or subultimate sugars, often determine the function(s) or recognition properties of glycoconjugates and are frequently altered upon malignant transformation $[6,9,19]$.

In the following, common patterns or tumor glycosylation are discussed. 
Increased branching of glycans

A common glycosylation aberration in malignancies constitutes the overexpression of complex $\beta-1,6$-branched $N$ linked glycans on the cell surface. This modification results from the enhanced transcription of Mgat5, in which product enzyme $N$-acetyl-glucosaminyltransferase V (GnT-V; GlcNAcT-V; MGAT5) catalyzes the transfer of GlcNAc residues to growing $N$-glycans, thus leading to 'multi-antennary' chains [27]. Increased expression of $\beta-1,6-$ branched $N$-linked glycans and MGAT5 is critically involved in tumor growth and metastasis [28-30], which seems to involve modified cell signaling and adhesion functions as a consequence of altered $\mathrm{N}$-glycosylation of cell surface receptors [31-33]. Altered N-glycosylation activity of MGAT5 has been shown to modulate cell apoptosis [34] and to promote cancer metastasis by affecting the stability or function of relevant proteins [32], including cadherins, integrins, or matriptase $[35,36]$. An increase of $\beta-1,6$-branched $N$-linked glycans on integrins has been reported to promote cell-extracellular matrix (ECM) interactions and tumor dissemination by enhanced adhesion to fibronectin and basement membrane laminin [37]. In addition, altered expression of MGAT5 in tumors not only benefits tumor metastasis but also impairs a correct antitumor immune response, as it has been shown to alter cytokine-mediated leukocyte signaling [31] and cytokine secretion by splenocytes and proliferation of $\mathrm{CD}^{+} \mathrm{T}$ cells [38]. Increased branching of glycans creates addition sites for terminal sialic acid residues leading to an increase in global sialylation [19], which may modulate interactions with sialic acid-specific-binding proteins, including selectins and siglecs (discussed below). Interestingly, MGAT5 itself also acts as an inducer of angiogenesis through a mechanism independent of glycosylation that involves the release of fibroblast growth factor-2 from cell surface or ECM heparin sulfate proteoglycan [39].

Mgat3 encodes $N$-acetylglucosaminyltransferase III (GnT-III; GlcNAcT-III; MGAT3), a glycosyltransferase that transfers a "bisecting" $N$-acetylglucosamine residue to a $\beta$-linked mannose in the $N$-glycan core. The presence of the bisecting $N$-acetylglucosamine inhibits the action of an $\alpha$-mannosidase, which is involved in the early biosynthetic steps of complex $\mathrm{N}$-glycans, including 1,6-branched $N$-linked glycans [24, 30]. MGAT3 activity with formation of bisecting $\mathrm{N}$-glycans may therefore regulate the synthesis of branched $\mathrm{N}$-glycans. In cancer, epigenetic control on the expression of MGAT3 seems to be responsible for the occurrence of bisected $\mathrm{N}$-glycans [40]. Overexpression of MGAT3 with concomitant decrease in $\beta-1,6$-branches suppresses the occurrence of experimental induced metastasis [30]. Decreased MGAT3 and increased MGAT5 expression was also observed in the highly metastatic derivative Skov3-ip cells of the ovarian adenocarcinoma cell line Skov3, which together may contribute to increased $\beta$-1,6-branching of $N$-linked glycans of metastatic cells [41]. MGAT3 and the bisecting GlcNAc have also been reported to reduce galectin-lattice dependent growth factor signaling leading to retarded tumor progression [42].

Taken together, the competition between MGAT5 and MGAT3 with altered expression of $\beta-1,6$-branched $N$-linked glycans or bisected plays a fundamental role in tumor growth and metastasis [32, 33]. The reduction of bisecting $N$-glycans and the concomitant increase of $\beta-1,6$ branched $N$-linked glycans, as a consequence of altered transcription of enzymes involved in $\mathrm{N}$-glycan synthesis, may lead to hypersialylation and modulate interactions with glycan-binding proteins that are relevant to tumor progression and immune escape.

\section{High-density glycosylation sites}

Focal enrichment of carbohydrate structures on the cell membrane may lead to different effects compared to the same glycans distributed at low density [18]. The focal density of glycolipids is influenced by coexisting membrane components and may affect oncogenetic events, tumor immunosurveillance or the recognition of tumorassociated antigens by diagnostic antibodies [18, 21]. Gangliosides are sialic acid-containing glycosphingolipids (GSLs) that contain a hydrophilic glycan head group linked to a ceramide anchor. Together with other membrane sphingolipids and cholesterol, gangliosides can segregate and form dynamic nanoscale "clusters", so-called lipid rafts; more highly unsaturated components, such as glycerophospholipids, provide the membrane with flexibility [21]. Through lateral carbohydrate-protein or carbohydrate-carbohydrate interactions gangliosides regulate signaling proteins in cis, such as epidermal growth factor receptor (EGFR) or vascular endothelial growth factor receptor (VEGFR), or even in trans, to modulate cellular differentiation, growth, and processes related to oncogenesis, metastasis or tumor immunity [21]. The association of gangliosides with cholesterol and other constituents of lipid rafts can lead to conformational changes in the glycolipid head group [21], and thereby affect carbohydrate-related functions of gangliosides. Ganglioside clustering may be of special importance for the function of organized structural domains, such as the immunological synapse formed between immunological effector cells and the targeted tumor cell [43]. Several antibodies recognizing tumor antigens, such as on melanoma or Burkitt lymphoma, were found to bind to gangliosides organized in clusters on tumor cells, but failed to bind when their density was below a certain threshold, suggesting altered density and 
structural characteristics of glycosylation sites of malignant cells compared to their healthy parental cells [18, 44].

Glycoproteins can also contribute to high-density glycosylation sites. Mucins harbor multiple serine and threonine O-glycosylation sites in a tandem-repeat domain of identical or highly similar sequences, and may exhibit altered density of tandem-repeat glycosylation in cancer compared to normal cells [20]. Carcinoma mucins, aberrantly glycosylated with either Tn or sTn, frequently form clusters on the tumor surface [20]. Such high-density glycosylation sites may lead to aberrant functions during the pathogenesis of cancer, affect immune responses, or, in analogy to clustered gangliosides, influence antibody attachment [9, 20].

Aberrant $O$-glycan synthesis resulting in truncated or incomplete glycans

A block of glycan synthesis often results in incomplete glycan structures, with or without accumulation of precursors [18]. As a consequence, malignant cells tend to express glycans with simpler structures than those found in normal cells [23]. In certain cases, the accumulation of specific incomplete glycans is detectable by diagnostic antibodies, such as sialyl Lewis $\mathrm{A}\left(\mathrm{Le}^{\mathrm{a}}\right)$, the glycan epitope of the tumor marker CA 19-9 for digestive organs, including pancreas and biliary tract [23]. Disialyl Le ${ }^{a}$, which is expressed on non-transformed cells, differs structurally by the presence of one extra sialic acid attached to the C-6 position of $\beta$ GlcNAc. Reduced transcription of the sialyltransferase responsible for the $\alpha 2-6$ sialylation at this position has been shown to be significantly decreased in cancer due to epigenetic silencing, resulting in loss of the more complex disialyl $\mathrm{Le}^{\mathrm{a}}$, and concomitant acquisition of sialyl $\mathrm{Le}^{\mathrm{a}}$ expression [45].

In analogy, sialyl $\mathrm{Le}^{\mathrm{x}}$ is utilized as a tumor marker. In contrast, its 6-sulfated derivative, sialyl 6-sulfo $\mathrm{Le}^{\mathrm{x}}$, is preferentially expressed in non-transformed cells [46]. Reduced expression of molecules responsible for sialyl Le ${ }^{\mathrm{x}}$ sulfation, including 6-sulfotransferase, PAPS synthase, and sulfate transporter was observed in cancer, whereby reduced transcription of the sulfate transporter diastrophic dysplasia sulfate transporter (DTDST) seems to have a dominant role for the reduction of sialyl 6-sulfo $\operatorname{Le}^{\mathrm{x}}$ and gain of non-sulfated sialyl Le ${ }^{\mathrm{x}}$ [47]. Silencing of DTDST in malignancies appeared to be epigenetically regulated, whereby histone modification rather than DNA methylation turned out to be responsible for controlling the expression of this gene.

Incomplete synthesis at early steps of $O$-linked glycan generation is linked to the appearance of short truncated glycans in cancer, such as the Tn (GalNAc- $\alpha 1-O$-Ser/Thr) and $\mathrm{T}$ (Thomsen-Friedenreich; Gal $\beta 1-3 \mathrm{GalNAc}-\alpha 1-O-\mathrm{Ser} /$
Thr) antigens, and their sialylated derivatives sTn and sT. The appearance of the Tn and sTn structures results from the lack of $\beta 1,3$-galactosyltransferase $(\mathrm{C} 1 \beta 3 \mathrm{Gal}-\mathrm{T})$ activity, which most probably originates from mutations in Cosmc [48]. Dysfunction of Cosmc, a chaperon responsible for folding and stability of $\beta 1,3$-galactosyltransferase ( $\mathrm{T}$ synthase), prevents the $\beta 1,3$-galactose extension of the simplest $O$-glycan Tn antigen, resulting in its accumulation. Similarly, decreased activity of the enzyme $\beta 1,6$ GlcNAc transferase (C2GnT1) prevents further extension of the $\mathrm{T}$ antigen (core 1 ) to form $O$-glycan core 2 , resulting in the accumulation of $\mathrm{T}$ or sT antigens in malignant tissues. The sialylation of Tn or T antigens, yielding sTn and sT antigens, prevents further glycan extension, which is often promoted by enhanced sialyltransferase expression in cancer, and has been associated with increased tumor growth, dissemination [8], and maturation and activity of dendritic cells, causing insufficient stimulation of $\mathrm{T}$ cells [49]. Mechanisms other than incomplete synthesis may contribute to enhanced formation of Tn, T, sTn or sT antigens in cancer, including enhanced availability of the substrate UDP-galactose or UDP-galactose transporter [8].

Truncated antigen expression in cancer is also evidenced by alterations in the $\mathrm{ABO}$ antigens. Reduced levels of $\mathrm{A}$ and $\mathrm{B}$ antigens have been reported in leukemia, bladder and oral cancer, among others [50, 51]. Specific allelic loss, in oral carcinomas, is in part responsible for the dysregulation in A and B antigens expression. Additionally, in bladder cancer loss of heterozygosity (LOH) and microsatellite instability is related to $\mathrm{ABO}$ modifications due to a chromosomal deletion at 9q34. Moreover, DNA methylation of the $\mathrm{CpG}$ islands in the proximal promoter of the $\mathrm{A} / \mathrm{B}$ encoding gene corresponds to the loss of blood antigens [50].

Importantly, the incomplete synthesis of glycans may result in the appearance of tumor-associated carbohydrate antigens of simpler structure that may exhibit altered binding capacity to glycan-binding proteins, including the sialic acid-binding receptors selectins and siglecs [23].

\section{Hypersialylation}

Hypersialylation, in one of the most common glycosylation changes in cancer and its aptitude to promote tumor growth was already recognized in the late 1960s [27, 52]. The enhanced density of sialylated epitopes on tumor cells compared to normal tissue has led to the establishment of novel tumor markers, such as CA19-9, SLX, CSLEX or NCC-ST-439, which have been successfully utilized in cancer diagnosis [18, 23]. Upregulation of sialyltransferases is one dominant mechanism underlying hypersialylation in cancer, the transcription of which is controlled by the proto-oncogenes, Ras and c-Myc, and can 
be induced by hypoxia [23, 52]. Furthermore, increased substrate availability, as a consequence of overexpression of genes involved in sialic acid biosynthesis or transport molecules, may lead to hypersialylation of cancer cells [23, 53]. Conversely, reduced degradation of sialoglycans due to declined expression of endogenous sialidases, enzymes that cleave sialic acids from glycans, has been proposed as a potential mechanism for tumor hypersialylation [54]. In addition, several forms of altered tumor glycosylation, including enhanced glycan branching and the accumulation of truncated sialic acid acceptor molecules, contribute to global tumor cell hypersialylation. Importantly, the clustering of sialoglycans in functional microdomains, such as lipid rafts [21] or the immunological synapse [43, 55], may significantly influence processes, such as tumor growth, dissemination or immunosurveillance.

\section{Expression of xenoglycans}

The predominant sialic acids on most mammalian cells are $\mathrm{N}$-glycolylneuraminic acid (Neu5Gc) and $\mathrm{N}$-acetylneuraminic acid (Neu5Ac). These two sialic acids differ by one oxygen atom which is added via hydroxylation of the cytidine-5'-monophosphate-Neu5Ac (CMP-Neu5Ac) into CMP-Neu5Gc. This reaction is catalyzed by the enzyme CMP-Neu5Ac hydroxylase (cmah) and is decisive in the levels of Neu5Gc glycoconjugates produced by a cell [5658]. In humans, the presence of the Neu5Gc variant is practically undetectable in normal cells, due to the inactivating deletion in the cmah gene [59]. Despite the genetic incapability of human cells to synthesize Neu5Gc, numerous reports have demonstrated the expression of this sialic acid variant on glycoproteins, but especially on gangliosides, by cells from various human malignancies, including colon and breast cancer [60, 61], melanoma [62], or retinoblastoma [63].

In humans, the absence, or very rare expression of glycoconjugates carrying Neu5Gc sialic acid in normal cells indicates that this sialic acid variant needs to be incorporated from external sources, such as human diet [64-66]. However, it is assimilated preferentially in cancer cells with respect to normal cells. Two causes have been associated to this differential expression. The increased metabolic rate of tumor cells is generally accepted as one of the causes [67] and is also relevant to the hypoxic condition inside the tumor mass [68]. It has been demonstrated that during hypoxia the transcription of Sialin, a sialic acid transporter, on cancer cells is induced [69]. This transporter mediates the incorporation of external sialic acid in vitro from the culture medium and, presumably, also facilitates this phenomenon in vivo [69] (Fig. 2). Several studies reported the occurrence of xenoantibodies to Neu5Gc in the serum of healthy individuals [70-72], that are eventually induced by dietary-Neu5Gc uptake via commensal bacteria [73, 74]. Evidence suggests that Neu5Gc-containing epitopes incorporated in human tissues from dietary sources (primarily red meats) may act as 'xeno-autoantigens' and in interaction with Neu5Gc-specific 'xeno-autoantibodies' may stimulate chronic inflammation and promote cancer, or other diseases, such as atherosclerotic vascular disease [73, 74]. This concept has recently been coined as 'xenosialitis hypothesis' [73].

Interestingly, anti-Neu5Gc antibodies exhibit dualistic effects on cancer growth in animal models, whereby lower antibody concentrations stimulate, and higher concentrations inhibit tumor growth $[72,75,76]$. Murine tumors expressing human-like levels of Neu5Gc exhibited accelerated growth in $\mathrm{Cmah}^{-1-}$ mice with a human-like deficiency of Neu5Gc, which was associated with the induction of anti-Neu5Gc antibodies and increased infiltration of inflammatory cells [76]. Similarly, passive transfer of anti-Neu5Gc antibodies promoted tumor growth at lower concentrations, while inhibitory effects were observed at higher concentrations [76]. This concentrationdependent dualistic effect is mediated by remarkably narrow ranges of antibodies and is also observed for other tumor-directed antibodies than anti-Neu5Gc, suggesting that these inverse hormesis effects represent a general characteristic of tumor-directed antibodies [75]. This biphasic tumor growth response may involve cancer promoting effects of M2-polarized tumor-associated macrophages at lower concentrations, and NK cell antitumor responses at higher, tumor-inhibiting concentrations [75].

\section{Immunological implications of tumor glycosylation}

Protein-glycan interactions have been reported to modulate the activity of multiple arms of cellular and humoral immunity including immune cells [77, 78], antibodies [79], and complement [80]. An abundance of glycan-binding proteins, i.e. lectins, exists that recognizes specific glycans and endows immune cells the capacity to decipher the "Glyco-Code" of healthy or diseased host cells and pathogens to induce or support immune responses, or to maintain immune homeostasis [81, 82]. Although certain families of lectins are defined by binding to a specific terminal carbohydrate moiety, e.g. to sialic acid for 'sialic acid-binding immunoglobulin-like lectins' (siglecs), the binding specificity of an individual family member often depends on additional parameters including carbohydrate linkage, type of subterminal structures, and chemical modifications (e.g. sulfation) [83].

Altered tumor glycosylation promotes or diminishes interactions with various lectin families including the 
Fig. 2 Incorporation of Neu5Gc-containing xenoglycans in human cancer. Neu5Gc is rare in human tissues due to the deletion of the enzyme that mediates hydroxylation of CMP-Neu5Ac into CMP-Neu5Gc (CMAH), and animal dietary sources may constitute the main supply of Neu5Gc. Under hypoxia, commonly found in human solid tumors, the expression of a lysosomal sialic acid transporter, Sialin, is enhanced. This leads to increased disponibility of free cytosolic Neu5Gc derived from lysosomal digested glycoproteins or -lipids, eventually resulting in overexpression of Neu5Gccontaining xenoglycans on the cancer cell surface

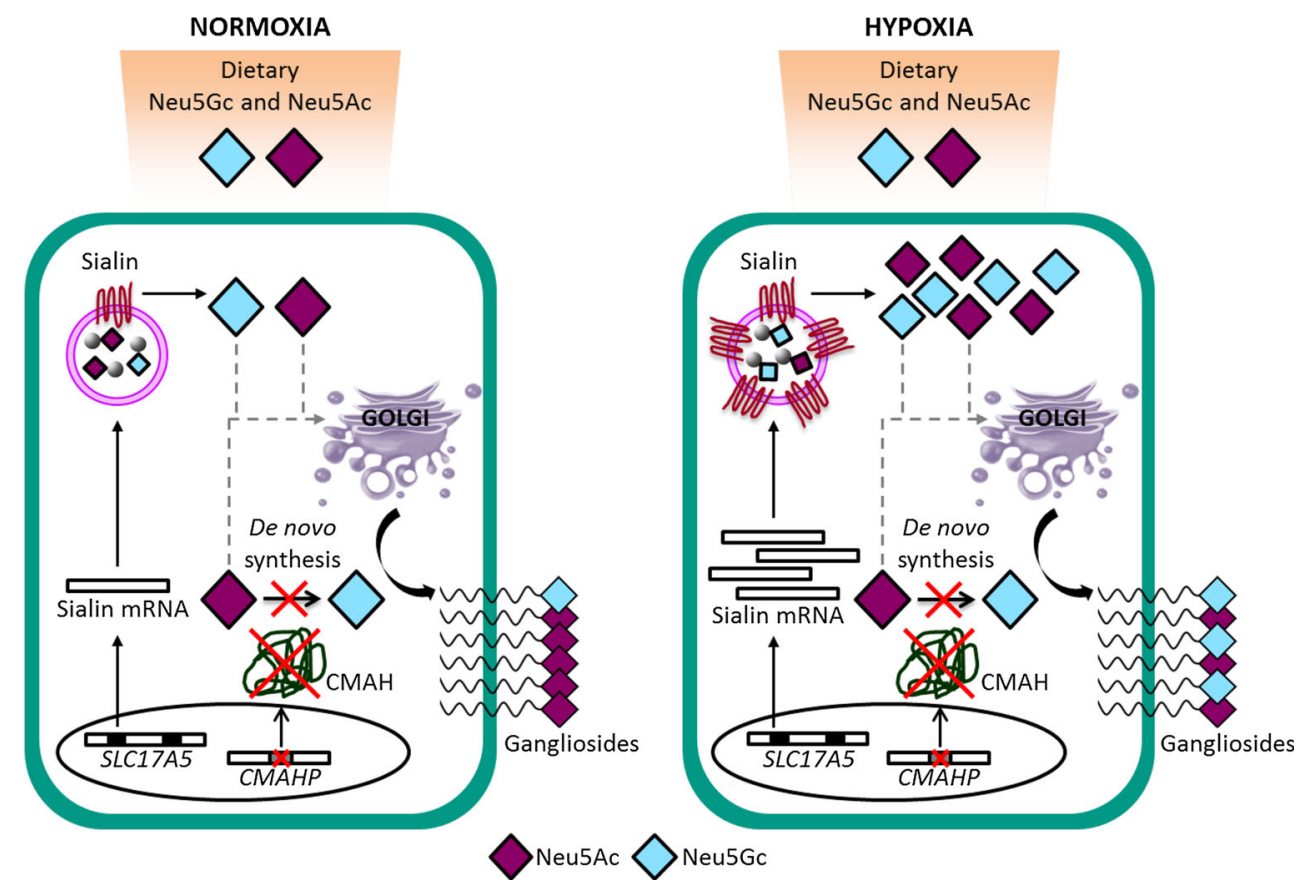

galectins that recognize the disaccharide $N$-acetyllactosamine [Gal $\beta(1-4)-G l c N A c ;$ LacNAc], the heterogenous C-type lectin receptors (CLRs), which predominantly recognize asialylated glycans (e.g. mannose-, fucose-, galactose-, or GalNAc-containing carbohydrates), and the sialic acid-binding selectins and siglecs. Notably, the atypical presence of sialic acids on cognate ligands, as often occurring in cancer, can reduce or abrogate recognition by lectins with specificity for asialylated glycans, such as the galectins [84].

Modified lectin-glycan interactions have been shown to affect both innate and adaptive immunity in cancer, eventually resulting in tumor-associated inflammation or undesired immune escape $[8,9,81]$. Thus, the outcome of an immune response is often critically influenced by the specific glycosylation profile of the malignant cell, which may involve the concerted and mutually non-exclusive action of lectins with different glycan-binding preferences. For instance, several different mechanisms involving glycan-lectin interactions have been found to influence natural killer (NK) cell-mediated tumor immunosurveillance (Fig. 3).

Recent studies indicate that overexpression of sialoglycan ligands for the inhibitory NK cell receptors Siglec-7 and -9 on tumor cells impairs NK cell antitumor defense mechanisms. While Siglec-7 is expressed on all human NK cells, Siglec-9 defines a subset of cytotoxic NK cells with enhanced chemotactic potential that is reduced in the peripheral blood of cancer patients [85]. Coating of tumor cells by passive membrane insertion with synthetic sialylated glycopolymers that serve as ligands for Siglec-7 protects from NK cell-mediated cytotoxicity [55]. Pretreatment of peripheral blood lymphocytes (PBL) with sialidase, to unmask Siglec-7 receptors bound in cis to ligand on the same cell surface, reduced cytotoxic responses towards cell lines expressing Siglec-7 ganglioside ligands in vitro, such as GD3 synthase-transfected P815 cells overexpressing GD3 [43] or ACHN cellsexpressing DSGb5 [86]. More recently, we showed that sialidase treatment of NK cells is dispensable for siglecmediated downregulation of NK cell responses by certain types of cancer that highly express Siglec-7 or -9 ligands [85]. Enzymatic removal of Siglec-7 or -9 ligands on tumor cells by sialidase or interference with blocking antibodies to Siglec-7 or -9 both dramatically enhanced the NK cellmediated killing of target cells, not only of NK cell-sensitive K562 cells, but also of presumably NK cell-resistant tumor cells. Furthermore, the recovery of peritoneally injected K562 and HeLa cells in humanized NOD-SCID$\gamma_{\mathrm{c}}^{-} /^{-}$(huNSG) mice with NK cells-expressing human Siglec-7 was significantly lower for desialylated tumor cells compared to Siglec-7/-9 ligands-expressing cells [85].

Removal of sialic acids on tumor cells has also been shown to enhance binding of the activating NK cell receptor NKG2D to ligands on the tumor cell and to enhance NKG2D-dependent NK cell cytotoxicity, and it was proposed that non-specific charge repulsion of sialic acid residues in their vicinity, or on NKG2D ligands themselves, might be responsible for this effect [87]. It is possible that tumor hypersialylation synergistically downregulates NK cell antitumor activity by attenuation of activatory NKG2D receptor-ligand interactions and 


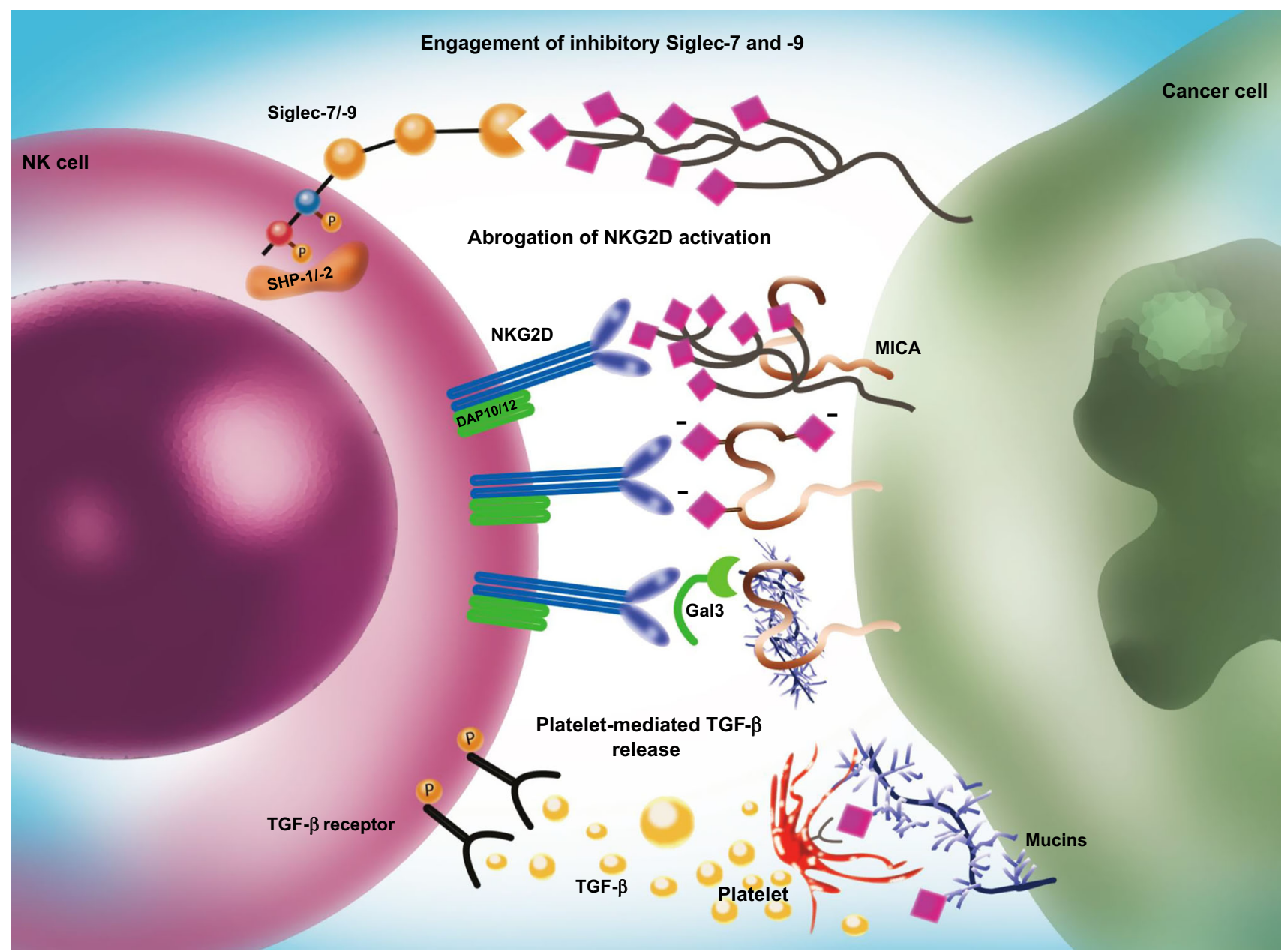

Fig. 3 The multiplicity of putative protein-glycan interactions that determines NK cell tumor immunosurveillance. Overexpression of specific sialic acid (purple diamonds)-containing carbohydrates (sialoglycans) leading to suppressed NK cell reactivity by engagement of their inhibitory Siglec-7 and -9 receptors. Interference of the

concomitant engagement of inhibitory siglec receptors on NK cells.

Another glycosylation-related mechanism that leads to tumor resistance towards NK cell lysis was reported by Tsuboi et al. [88] and involves the presence of poly- $\mathrm{N}$ acetyllactosamine on the NKG2D-binding site of its ligand MHC class I-related chain A (MICA) on tumor cells overexpressing the glycosyltransferase $\mathrm{C} 2 \mathrm{GnT}$. In this study, soluble lectin Galectin-3 was found to bind to poly$N$-acetyllactosamine on MICA, thereby inhibiting the NKG2D-MICA interaction with concomitant reduction of NK cell function, including IFN- $\gamma$ and granzyme B secretion and tumor lysis. Expression of $\mathrm{C} 2 \mathrm{GnT}$ was found to be higher in metastatic bladder cells, and based on patient data; Tsuboi et al. concluded that the expression of C2GnT might be a more useful prognostic indicator than pathological grade and stage in bladder tumors. interaction of activatory NK cell receptor NKG2D with its ligand MICA on the cancer cell, as a result of enhanced MICA sialylation, masking by sialoglycans, or Galectin-3 (Gal3) binding to glycosylated MICA. TGF- $\beta$ release of P-selectin-sialoglycan bound platelets, as found in tumor emboli, may result in suppressed NK cell activity

Platelets contribute to tumor dissemination by formation of tumor microemboli, whereby platelet adhesion to tumor cells is primarily mediated by $\mathrm{P}$-selectin and its interaction with $\operatorname{sLe}^{\mathrm{x} / \mathrm{a}}$-carrying structures on tumor cells [89]. For instance P-selectin mediates the adhesion of platelets to neuroblastoma and non-small cell lung cancer cells [90]. Similarly sulfated ceramides in the colon carcinoma MC38 cells that serve as ligands for P-selectin foster the adhesion of activated platelets to tumor cells [91]. P-selectin mediated adhesion of platelets not only enhances metastatic spread and intravascular tumor-cell survival $[8$, 92], but appears to shield circulating tumor cells from NK cell lysis [93-95]. Recently, it has been shown that plateletderived transforming growth factor $\beta$ (TGF- $\beta$ ) impairs NK cell antitumor immunity by downregulation of the NK cell activating receptor NKG2D with concomitant reduction of NK cell degranulation, cytokine production and 
cytotoxicity [95]. The enhanced expression of P-selectin sialoglycan ligands on tumor cells correlates with cancer progression [8], which may be attributed to events that involve both endothelial and platelet P-selectin that together promote metastatic tissue colonization and immune escape.

Altered glycosylation patterns may not only protect tumor cells from innate immunity, but may shape emerging adaptive immune responses by the display of specific glycan ligands to lectins on antigen-presenting cells (APCs) [78, 96]. Dendritic cells (DCs) express myriad glycan-binding receptors, including siglecs and various members of the heterogenous C-type lectin family, such as DC-SIGN, BDCA2, DCIR and MICL, which modulate toll-like receptor (TLR) signaling, or receptors that directly influence gene expression, eventually by involvement of nuclear factor- $\mathrm{KB}(\mathrm{NF}-\kappa \mathrm{B})$ as in the case of Dectin 1 [82]. Depending on the tumor 'glycosylation signature' different lectins will be engaged that trigger DC programs that potentiate or suppress antitumor responses [81]. For instance, while conjugation of specific glycan ligands might lead to enhanced presentation of tumor-associated antigens to $\mathrm{CD}^{+} \mathrm{T}$ cells or cross-presentation to $\mathrm{CD} 8^{+} \mathrm{T}$ cells [97, 98], Lewis glycans expressed on carcinoembryonic antigen (CEA) or CEA-related cell adhesion molecule-1 (CEACAM-1), in contrast, have been shown to negatively affect DC function, which may result in impaired antitumor responses [99].

Galectins can be released by tumor cells or immune cells and have caught special attention in terms of their dual role in antitumor defense or immune escape. Different members of this family have shown to modulate the survival and function of both myeloid and lymphoid leukocytes, resulting either in pro- or anti-inflammatory immune responses [14]. Tumor secretion of galectins is a mechanism adopted by a wide range of malignancies to promote an immunosuppressive environment [81]. Besides impairing NK cell responses to tumor cells (see above), galectins have also been shown to affect adaptive immune responses by attenuating DC responses, limiting $\mathrm{T}$ cell survival and favoring anergy or exhaustion of tumor-specific $\mathrm{T}$ cells and the expansion of regulatory $\mathrm{T}$ cells (Tregs) $[8,14,81]$.

\section{The role of sialic acid-binding proteins in cancer}

Until the 1980s, the functions of sialic acids were primarily associated with providing negative charge and hydrophilicity to vertebrate cell surfaces, masking of glycan ligands, or serving as attachment sites of pathogens and toxins. More recent research revealed a functional role of their interaction with sialic acid-binding proteins in multiple biological systems and conditions, including immunity and cancer [80]. Several classes of sialic acidbinding proteins, including siglecs, selectins and complement factor $\mathrm{H}$, have been shown to be critically involved in tumor progression and antitumor immunity, often as a functional consequence of enhanced or altered sialylation patterns of cancer cells. For instance, hypersialylation has been shown to endow tumor cells the capacity to evade complement-mediated attack by binding of Factor $\mathrm{H}$, which negatively regulates the alternative complement pathway [100-102]. While the role of siglecs and selectins in NK cell-mediated antitumor defense has been discussed above, further tumor-related aspects of these receptors are discussed next.

\section{Siglecs in cancer}

Siglecs constitute a family of cell surface receptors with an extracellular domain composed of a sialoglycan-binding $\mathrm{N}$-terminal V-set domain, a variable number of $\mathrm{C} 2$-set Ig domains, a transmembrane region and a cytoplasmic tail, latter of which in most Siglec members contain one or more membrane-proximal immunoreceptor tyrosine-based inhibitory motif (ITIM) and a membrane-distal ITIM-like motif [83, 103-105]. The siglec family comprises an evolutionary conserved group, including sialoadhesin (Siglec1), CD22 (Siglec-2), myelin-associated glycoprotein (MAG; Siglec-4) and Siglec-15, a group of rapidly evolving siglecs including CD33 and the CD33 (Siglec-3)related siglecs (CD33rSiglecs; Siglec-5 to -14 , and -16) [105-107]. The species-related differences of CD33rSiglecs require special attention for the design of experimental in vivo models $[85,108]$. Besides adhesion, endocytosis and pathogen internalization, siglec functions include immunoregulatory processes [103, 105, 109], such as inhibition of cellular activity and proliferation, or regulation of leukocyte survival [110-114]. The siglec-based immunoregulatory system seems to include naturally occurring and anti-idiotypic antibodies to siglecs [115117], which may contribute to the anti-inflammatory effects of high-dose intravenous immunoglobulin (IVIG) [79, 114, 118-120]. It has been proposed that by their capacity to discriminate between PAMP and 'SAMP' or DAMP, siglecs may play a role in the protection of self tissue as well as the repression of tissue damage-induced immune responses [16, 121]. By hypersialylation, as display of 'enhanced self', tumors seem to exploit inhibitory siglecs for immune evasion.

Recently, we demonstrated overexpression of Siglec-7 and -9 ligands on melanoma cells in histological skin sections and on primary CLL and AML cells from patients [85]. In a subsequent, independent study, the upregulation of Siglec-9 ligands in sections of colorectal, breast, 
prostate, ovarian, and non-small-cell lung cancer (NSCLC) was reported [122]. In contrast, no overexpression of Siglec-7/-9 ligands was found in basal cell carcinoma (BCC), squamous cell carcinoma (SCC), and cutaneous $\mathrm{T}$ cell lymphoma (CTCL). Furthermore, Siglec-7/-9 ligand expression was heterogeneous in a broad range of different cell lines. These findings point to some degree of variability in terms of siglec ligands expression in tumors of different tissue-specific origin, which has implications in terms of tumor immune evasion strategies or potential therapeutic approaches involving siglecs or their ligands. Siglec-7/-9 ligand expression may also occur in certain non-malignant tissues, and it has been hypothesized that loss of immunosuppressive glycans during colonic carcinogenesis enhances inflammatory mediator production [123].

Recent evidence suggests that overexpression of native siglec ligands by tumor cells dampens innate immune responses mediated by NK cells [85] and neutrophils [122]. Läubli et al. [122] reported that engagement of human Siglec-9 in vitro and of related murine Siglec-E in vivo inhibits the tumoricidal activity of neutrophils. Interestingly, although tumors developed later in Siglec-E null $\left(\mathrm{SigE}^{-1-}\right)$ mice in a 3-methylcholanthrene (MCA) model of carcinogenesis, they grew faster and larger, once they appeared, and exhibited increased infiltration of tumor growth-promoting M2 macrophages. In line with the proangiogenic function of M2 macrophages, increased angiogenesis was also observed in tumors of $\mathrm{SigE}^{-1-}$ mice. The authors hypothesized that in their model, the expression of Siglec-E ligands might efficiently suppress innate immunity during early tumorigenesis or metastasis, however, at a later stage the expression of Siglec-E ligands might induce polarization to M1 macrophages, but eventually, because the tumor is already at a larger size, this does not lead to rejection. Furthermore, these investigators found an association of Siglec-9 polymorphism with early survival of NSCLC patients [122]. Together, these data suggest a dual function of myelomonocytic cells in cancer progression and that targeting siglec receptor-ligand interactions might be beneficial in the correct temporal and situative context. In a recent study, transgenic mice expressing a soluble form of human Siglec-9 (sSiglec-9) showed longer survival and less advanced tumor progression compared to non-transgenic mice following intraperitoneally transplants of mouse mammary tumor cells-expressing human MUC1 [124]. Although, as proposed by the authors, sSiglec-9 in this model might involve competitive inhibition of MUC1 binding to certain receptors, the identity and tissue expression of latter remains unclear, especially given that Siglec-9 is not naturally expressed in rodents.
While the exact sialoglycan ligands of siglecs expressed on distinct types of tumors still remain elusive, a number of mucins have been shown to bind to members of this lectin family and to eventually regulate leukocyte functions as cell membrane bound or soluble factor [125-127], including binding of the tumor marker CA125/MUC16 that interacts with Siglec-2, $-3,-7,-9$ and -10 [128, 129]. Notably, siglec interactions with their mucin counterreceptors might influence tumor progression in two directions [130], i.e. transduction of inhibitory signals in immune cells by siglecs, or by induction or modulation of mucinmediated signaling pathways [130, 131]. Vascular adhesion protein-1 (VAP-1) was identified as a binding partner of Siglec-9 and -10, which might be exploited for imaging of vasculature at sites of inflammation and cancer [132, 133]. Siglecs themselves given their function, their cell-specific expression on leukocyte subsets and their endocytotic capacities, exhibit properties that might be exploited for cell-directed therapy. Various approaches targeting siglecs are currently tested in pre-clinical and clinical studies for the treatment of leukemia and inflammatory disorders [105, 134-136].

\section{Selectins in malignant disease}

Selectins compose a family of C-type lectins expressed on the surface of leukocytes and endothelial cells, known to mediate cellular adhesion processes in immune responses or in cancer $[23,137,138]$. Selectins are type-I receptors with an extracellular part comprising a C-type lectin domain, an EGF domain and a variable number of short consensus repeat domains, as well as a transmembrane and a short cytoplasmic tail of maximally 35 aa that can interact with cytoskeleton components and is responsible of targeting selectins to different cellular compartments [139]. This receptor family is constituted of three members: E-selectin expressed on endothelial cells, L-selectin on leukocytes and P-selectin on platelets and endothelial cells. In contrast to L-selectins that are constitutively expressed on all myeloid cells and on subsets of bloodborne lymphocytes, E- and P-selectin expression on endothelium or platelets is mainly induced following cellular activation. P-selectin is stored in the Weibel-Palade bodies of endothelial cells or $\alpha$-granules of platelets, and can be rapidly redistributed to the cell membrane following cellular activation. Selectins can also be found in soluble form in the circulation mainly associated with damage of the endothelium, cell activation and certain pathological conditions [140-142].

Selectins interact by means of their ligand-binding domains with sulfated glycoconjugates on a broad range of glycoproteins and -lipids, including mucins, heparin, and 
heparan sulfate [143]. The minimal recognition motif for selectins is Lewis structures, specifically sLe ${ }^{\mathrm{a}}$ and $\mathrm{sLe}^{\mathrm{x}}$, the generation of which involves the $\alpha(1,3)$-fucosyltransferases IV or VII (FUT4 and FUT7), $\alpha 2,3$-sialyltransferases, $\beta 1,4$-galactosyltransferases and $N$-acetyl-glucosaminyltransferases [137]. Carcinoma mucins carrying $\mathrm{sLe}^{\mathrm{x} / \mathrm{a}}$ moieties represent major selectin ligands on cancer cells; other selectin ligands on malignant cells include CD24, CD44, death receptor 3, ESL-1 and PSGL-1 [137]. The acquisition of selectin ligands seems to permit cancer cells to engage in similar mechanisms of adhesion and extravasation as used by leukocytes [23, 137, 144]. Furthermore, selectins seem to promote metastasis by shaping the metastatic niche [137]. Indeed, mice that are deficient in FUT7 and display a minimal amount of selectin ligands exhibit reduced metastasis formation in comparison with their wild-type counterparts [145]. Attenuation of tumor metastasis was observed in mice deficient in L- and P-selectins, or mice treated with heparin, as a primary consequence of P-selectin inhibition [146]. Similarly, formation of spontaneous distant metastases of the human $\mathrm{OH}-1$ small cell lung cancer (SCLC) cell line xenografted into E-/P-selectindeficient mice was significantly reduced [147]. By intravital microscopy of murine mesenterial vasculature the authors found that the $\mathrm{OH}-1$ cells mimic the selectin-dependent rolling behavior of leukocytes along vessel walls.

The different selectins, E-, L- and P-selectin, seem to synergistically act in the tissue colonization by mediating heterotypic interactions between cancer cells, leukocytes and endothelial cells within the metastatic microenvironment [8, 137]. Tumor embolus formation during intravascular circulation or after microvascular arrest of tumor cells in distant organs involves P-selectin-mediated cancer cell-platelet interactions [89]. These events lead to local activation of endothelial cells recruitment and activation of leukocytes that depend on both L-selectin and selectin ligands (e.g. PSGL-1) on leukocytes, latter of which may bind either to vascular selectins, P- and/or E-selectins, or through binding to L-selectin on already adherent leukocytes [145, 148]. Recruited leukocytes, including monocytes and descendant macrophages, seem to increase vascular permeability and transendothelial migration of cancer cells, or may eventually contribute to local immunosuppression [137]. Given that selectins are predominantly implicated in hematogenous metastasis, selectin-targeting therapeutics might be beneficial in the prevention of cancer cell dissemination eventually after surgical removal of the primary tumor. Notably, unfractioned and certain low molecular weight heparins exhibit both anticoagulant and selectin blocking activity and are currently evaluated in clinical trials administered in addition to adjuvant systemic treatment after surgery of localized tumors [137].

\section{Xeno-autosialylation: Neu5Gc gangliosides in cancer}

In humans the repertoire of sialoglycans, the sialome [26], undergoes dramatic modifications upon malignant transformation that not only relates to hypersialylation of endogenous Neu5Ac glycans, but also to neoexpression of Neu5Gc-containing xenoglycans. To date the role of endogenous Neu5Ac-gangliosides in tumor biology and immunosuppression has received considerable attention. Overexpression of this kind of gangliosides can provoke a reduction on tumor cell motility and a propensity to undergo apoptosis [149-151]. Also, it is well established that $N$-acetyl GM3 ganglioside (NAcGM3) interacts with the epidermal growth factor receptor (EGFR) inhibiting the EGF-induced receptor activation [152]. Additionally, various Neu5Ac-gangliosides are known to promote a suppressive tumor microenvironment [21, 43, 153, 154]. In contrast, the biological consequences of aberrant expression of xenogeneic Neu5Gc-gangliosides for tumor biology have not been studied in depth. Experimental evidence in this sense is derived from murine tumor cell lines in which the cmah gene has been knocked-out and the Neu5Gc sialic acid has been incorporated exogenously [155]. In this sense, Gabri et al. [156] demonstrated that mouse B16 melanoma and F3II mammary carcinoma cells induced a higher number of lung metastasis and increased tumor progression after in vitro incorporation of Neu5Gc-rich mucin on the membrane. Similarly, GM3-expressing 3LLD122 Lewis lung carcinoma cells produced more experimental lung tumor metastasis, if they were pre-incubated with Neu5Gc [157]. More recently, it has been published that silencing the cmah gene in $N$-glycolyl GM3 ganglioside (NGcGM3)-expressing L1210 mouse lymphocytic leukemia B cells caused a marked expression of NAcGM3 and an impaired tumor development in vivo [155]. These observations contrast with a report showing that B16 melanoma cells transfected with the cmah gene and thus expressing NGcGM3 displayed a reduced tumor growth as compared with the parental cell line [158]. Other evidence supporting the concept that Neu5Gc expression promotes tumor progression is the correlation of NGcGM3 expression with the stage of malignancy, with enhanced expression in metastatic lesions [159]. Furthermore, xenosialitis induced by anti-Neu5Gc antibodies may promote cancer progression by enhancing tumor-related inflammation, as discussed above and reviewed in [73, 74]. Yet, other work points to a immunosuppressive capacity of both Neu5Ac and Neu5Gc-gangliosides, which exhibited similar capacity to downmodulate CD4 molecules on the T lymphocyte surface or to inhibit dendritic cells differentiation and maturation in vitro $[160,161]$. Taken together, current evidence indicates that preferential expression of the Neu5Gc-glycoconjugates on tumor cells could provide a 
mechanism utilized by cancer to promote tumor progression, metastasis and to shape immune responses (reviewed in [73]).

Targeting xenogenic TACA for cancer immunotherapy appears as an attractive option, including tumor-associated sialoglycans that aberrantly express Neu5Gc (discussed above).

The 'non-human' glycolipid NGcGM3 was reported in the 1990s to be present in human breast tumors while it remained undetectable in normal breast tissue [61]. Subsequently, several other studies have been conducted to address its expression in other types of malignancies [62, 162-164].

Recent studies extend or reaffirm the presence of NGcGM3 ganglioside in NSCLC, digestive system tumors, primary lymphoid tumors, pediatric nervous system tumors, sarcomas, thyroid carcinomas, and oral cavity melanomas $[62,162-165]$. Noteworthy a significantly elevated expression of this target ranged from $33 \%$ of studied cases in esophagus cancer up to $100 \%$ of stomach, large intestine and pancreatic tumors [163].

As previously stated, one of the more striking features of this glycolipid is its tumor-restricted character. While almost $50 \%$ of NSCLC samples are highly positive for NGcGM3, no Neu5Gc-containing ganglioside expression was detected in normal lung tissues [165]. Blanco et al. [164] extended the same finding to normal tissues of skin, esophagus, stomach, large intestine, liver, pancreas, testis, prostate, kidney, urinary bladder, brain, cerebellum, spinal cord, peripheral nerves, thymus, tonsils, lymph nodes, spleen, heart, arteries, veins, muscles, pituitary and thyroid glands. Only a weak reaction of a specific anti- NGcGM3 monoclonal antibody (14F7 mAb) with mucous cells from small intestine samples was observed in one-third of the cases [164]. In addition, ten oral melanocytic nevi evidenced no reactivity with $14 \mathrm{~F} 7 \mathrm{mAb}$ [62].

Racotumomab (formerly known as 1E10; Vaxira ${ }^{\circledR}$ ) is an anti-idiotypic antibody obtained from mice immunized with the murine IgM P3 (coupled to KLH in adjuvant), specifically reacting with the tumor-associated ganglioside NGcGM3 and other Neu5Gc-containing gangliosides. Anti-idiotypic racotumomab acts as a molecular mimicry of these parental gangliosides. More than a decade after the racotumomab was first described by Vazquez et al. [166], recent clinical trials show promising results of a vaccine formulation of aluminium hydroxide-precipitated racotumomab. In a study of advanced non-small cell lung cancer (NSCLC), the racotumomab vaccine was shown to be immunogenic in 16 out of 20 NSCLC patients, raising detectable serum levels of specific IgM and IgG antibody responses against NGcGM3 ganglioside. Hyperimmune patient sera were able to induce complement-independent cell death of NGcGM3-expressing X63 murine myeloma target cells [167]. Another recent randomized, multicenter, placebo-controlled clinical trial in advanced NSCLC patients indicated a clinically relevant improvement in overall survival and progression-free survival for racotumomab-alu-treated patients in comparison with the placebo group [168]. Noteworthy, the capacity of induced serum IgM anti-NGcGM3 antibodies to bind or destroy at least $30 \%$ of antigen positive murine leukemia L1210 cells was clearly associated with longer overall survival [168]. These studies provide compelling evidence that points to NGcGM3 as a clinically meaningful therapeutic target $[159,169]$.

As an alternative approach, a cancer vaccine has been developed by combining chemically unmodified NGcGM3 ganglioside with the hydrophobic outer membrane protein complex derived from Neisseria meningitides [170]. Very small-sized proteoliposomes (VSSP) with nanometric diameters were obtained and significant humoral immune responses in mice and monkeys against the highly tolerated GM3 and NGcGM3 were induced by vaccination [170]. A controlled Phase II clinical trial of the NGcGM3/VSSP vaccine was conducted in 79 patients with metastatic breast cancer [171]. In the intent to treat analysis, there was a trend toward a survival advantage for the vaccine group and this effect was significant for patients with non-visceral metastasis [171]. Similarly patients with metastatic cutaneous melanoma were included in a Phase I/II clinical trial and treated with a new formulation of the NGcGM3/VSSP vaccine by the subcutaneous route [172]. Objective responses or stable disease was observed in $38.46 \%$ of patients with a global median overall survival of 20.20 months [172].

While these results are rather encouraging, a more firm clinical validation of this particular glycan NGcGM3 as a target of cancer immunotherapy for different malignancies, may be expected soon from ongoing Phase III clinical studies evaluating Vaxira and NGcGM3/VSSP vaccines (to be published).

\section{Conclusions}

Cells exhibit differential glycosylation patterns that are differentiation and cell type-specific [5], but is subject to significant modification under distinct physiological or pathological conditions [7, 23]. Glycosylation changes, as a consequence of epigenetic or genetic events, are a hallmark of tumor development. Since the first demonstration of altered glycosylation in transformed cells by Meezan et al. in 1969 [173], many tumor-associated carbohydrate antigens have been diagnostically utilized as tumor markers. Although the functional consequences of 
altered tumor glycosylation remain to be further explored, several promising therapeutic strategies targeting glycans, glycan-binding proteins, or protein-glycan interactions have been proposed or are under clinical evaluation and have been extensively reviewed elsewhere [9, 19]. Glycanbased therapeutics include, among others, tumor vaccines based on carbohydrate-mimetic peptides [174] or antiidiotypic antibodies (e.g. racotumomab), natural or synthetic glycans to block glycan-binding proteins or glycanmodifying enzymes [9, 19, 92, 175], as well as antibodies or glycan-coated nanoparticles for cell-directed therapy $[105,135]$.

Evidence suggests that tumor cells acquire in a 'microevolutionary' process [9, 27], a glycosylation profile that provides them advantages in terms of tumor growth, dissemination and immune escape. A better understanding of the immunomodulatory glycosylation signals and codes that are sent out by tumor cells, and received and deciphered by detection systems of different arms of the immune system, may lead to novel and improved therapeutic strategies, not only for cancer, but also for autoimmune disease and transplantation.

Acknowledgments Research by SVG is supported by the Swiss National Science Foundation (Grant No. 310030_135734), the Bulgarian-Swiss Research Program (BSRP) No. IZEBZO_142967, Swiss Cancer Research (KFS-3248-08-2013) and CSL Behring AG, Bern, Switzerland. The authors thank Aldona von Gunten for full illustration of Fig. 3 and assistance with Fig. 2.

\section{References}

1. Hart GW, Copeland RJ (2010) Glycomics hits the big time. Cell 143(5):672-676. doi:10.1016/j.cell.2010.11.008

2. Schachter H, Freeze HH (2009) Glycosylation diseases: quo vadis? Biochim Biophys Acta 1792(9):925-930. doi:10.1016/j. bbadis.2008.11.002

3. Varki A (2006) Nothing in glycobiology makes sense, except in the light of evolution. Cell 126(5):841-845. doi:10.1016/j.cell. 2006.08.022

4. Gagneux P, Varki A (1999) Evolutionary considerations in relating oligosaccharide diversity to biological function. Glycobiology 9(8):747-755

5. North SJ, von Gunten S, Antonopoulos A, Trollope A, MacGlashan DW Jr, Jang-Lee J, Dell A, Metcalfe DD, Kirshenbaum AS, Bochner BS, Haslam SM (2012) Glycomic analysis of human mast cells, eosinophils and basophils. Glycobiology 22(1):12-22. doi:10.1093/glycob/cwr089

6. Stanley P, Cummings RD (2009) Structures common to different glycans. In: Varki A, Cummings RD, Esko JD et al (eds) Essentials of glycobiology, 2nd edn. Cold Spring Harbor, New York

7. Ohtsubo K, Marth JD (2006) Glycosylation in cellular mechanisms of health and disease. Cell 126(5):855-867. doi:10.1016/j. cell.2006.08.019

8. Häuselmann I, Borsig L (2014) Altered tumor-cell glycosylation promotes metastasis. Front Oncol 4:28. doi:10.3389/fonc.2014. 00028
9. Fuster MM, Esko JD (2005) The sweet and sour of cancer: glycans as novel therapeutic targets. Nat Rev Cancer 5(7):526-542. doi:10.1038/nrc1649

10. Gabius HJ (2000) Biological information transfer beyond the genetic code: the sugar code. Naturwissenschaften 87(3): 108-121

11. Stowell SR, Arthur CM, McBride R, Berger O, Razi N, Heimburg-Molinaro J, Rodrigues LC, Gourdine JP, Noll AJ, von Gunten S, Smith DF, Knirel YA, Paulson JC, Cummings RD (2014) Microbial glycan microarrays define key features of hostmicrobial interactions. Nat Chem Biol 10(6):470-476. doi:10. 1038/nchembio. 1525

12. von Gunten S, Smith DF, Cummings RD, Riedel S, Miescher S, Schaub A, Hamilton RG, Bochner BS (2009) Intravenous immunoglobulin contains a broad repertoire of anticarbohydrate antibodies that is not restricted to the $\mathrm{IgG} 2$ subclass. J Allergy Clin Immunol 123(6):1268-1276. doi:10.1016/j.jaci.2009.03. 013

13. Houzelstein D, Goncalves IR, Fadden AJ, Sidhu SS, Cooper DN, Drickamer K, Leffler H, Poirier F (2004) Phylogenetic analysis of the vertebrate galectin family. Mol Biol Evol 21(7):1177-1187. doi:10.1093/molbev/msh082

14. Liu FT, Rabinovich GA (2005) Galectins as modulators of tumour progression. Nat Rev Cancer 5(1):29-41. doi:10.1038/ $\operatorname{nrc} 1527$

15. Varki A, Schauer R (2009) Sialic acids. In: Varki A, Cummings RD, Esko JD et al (eds) Essentials of glycobiology, 2nd edn. Cold Spring Harbor, New York

16. Varki A (2011) Since there are PAMPs and DAMPs, there must be SAMPs? Glycan "self-associated molecular patterns" dampen innate immunity, but pathogens can mimic them. Glycobiology 21(9):1121-1124

17. Macauley MS, Paulson JC (2014) Immunology: glyco-engineering 'super-self'. Nat Chem Biol 10(1):7-8. doi:10.1038/ nchembio. 1415

18. Hakomori S (1984) Tumor-associated carbohydrate antigens. Annu Rev Immunol 2:103-126. doi:10.1146/annurev.iy.02. 040184.000535

19. Dube DH, Bertozzi CR (2005) Glycans in cancer and inflammation-potential for therapeutics and diagnostics. Nat Rev Drug Discov 4(6):477-488. doi:10.1038/nrd1751

20. Hollingsworth MA, Swanson BJ (2004) Mucins in cancer: protection and control of the cell surface. Nat Rev Cancer 4(1):45-60. doi:10.1038/nrc1251

21. Krengel U, Bousquet PA (2014) Molecular recognition of gangliosides and their potential for cancer immunotherapies. Front Immunol 5:325. doi:10.3389/fimmu.2014.00325

22. Kufe DW (2009) Mucins in cancer: function, prognosis and therapy. Nat Rev Cancer 9(12):874-885. doi:10.1038/nrc2761

23. Kannagi R, Sakuma K, Miyazaki K, Lim KT, Yusa A, Yin J, Izawa M (2010) Altered expression of glycan genes in cancers induced by epigenetic silencing and tumor hypoxia: clues in the ongoing search for new tumor markers. Cancer Sci 101(3):586-593. doi:10.1111/j.1349-7006.2009.01455.x

24. Stanley P, Schachter H, Taniguchi N (2009) N-glycans. In: Varki, Cummings RD, Esko JD et al (eds) Essentials of glycobiology, 2nd edn. Cold Spring Harbor, New York

25. Brockhausen I, Schachter H, Stanley P (2009) $O$-GalNAc glycans. In: Varki A, Cummings RD, Esko JD et al (eds) Essentials of glycobiology, 2nd edn. Cold Spring Harbor, New York

26. Cohen M, Varki A (2010) The sialome-far more than the sum of its parts. OMICS 14(4):455-464. doi:10.1089/omi.2009.0148

27. Varki A, Kannagi R, Toole BP (2009) Glycosylation changes in cancer. In: Varki A, Cummings RD, Esko JD et al (eds) Essentials of Glycobiology, 2nd edn. Cold Spring Harbor, New York 
28. Dennis JW, Laferte S, Waghorne C, Breitman ML, Kerbel RS (1987) Beta 1-6 branching of Asn-linked oligosaccharides is directly associated with metastasis. Science 236(4801):582-585

29. Granovsky M, Fata J, Pawling J, Muller WJ, Khokha R, Dennis JW (2000) Suppression of tumor growth and metastasis in Mgat5-deficient mice. Nat Med 6(3):306-312. doi:10.1038/ 73163

30. Yoshimura M, Nishikawa A, Ihara Y, Taniguchi S, Taniguchi N (1995) Suppression of lung metastasis of B16 mouse melanoma by $N$-acetylglucosaminyltransferase III gene transfection. Proc Natl Acad Sci USA 92(19):8754-8758

31. Partridge EA, Le Roy C, Di Guglielmo GM, Pawling J, Cheung P, Granovsky M, Nabi IR, Wrana JL, Dennis JW (2004) Regulation of cytokine receptors by Golgi $N$-glycan processing and endocytosis. Science 306(5693):120-124. doi:10.1126/science. 1102109

32. Zhao YY, Takahashi M, Gu JG, Miyoshi E, Matsumoto A, Kitazume S, Taniguchi N (2008) Functional roles of $N$-glycans in cell signaling and cell adhesion in cancer. Cancer Sci 99(7):1304-1310. doi:10.1111/j.1349-7006.2008.00839.x

33. Taniguchi N, Miyoshi E, Ko JH, Ikeda Y, Ihara Y (1999) Implication of $N$-acetylglucosaminyltransferases III and $\mathrm{V}$ in cancer: gene regulation and signaling mechanism. Biochim Biophys Acta 1455(2-3):287-300

34. Inamori K, Gu J, Ohira M, Kawasaki A, Nakamura Y, Nakagawa T, Kondo A, Miyoshi E, Nakagawara A, Taniguchi N (2006) High expression of $\mathrm{N}$-acetylglucosaminyltransferase $\mathrm{V}$ in favorable neuroblastomas: involvement of its effect on apoptosis. FEBS Lett 580(2):627-632. doi:10.1016/j.febslet.2005.12.089

35. Ihara S, Miyoshi E, Ko JH, Murata K, Nakahara S, Honke K, Dickson RB, Lin CY, Taniguchi N (2002) Prometastatic effect of $\mathrm{N}$-acetylglucosaminyltransferase $\mathrm{V}$ is due to modification and stabilization of active matriptase by adding beta 1-6 GlcNAc branching. J Biol Chem 277(19):16960-16967. doi:10.1074/jbc. M200673200

36. Ihara S, Miyoshi E, Nakahara S, Sakiyama H, Ihara H, Akinaga A, Honke K, Dickson RB, Lin CY, Taniguchi N (2004) Addition of beta1-6 GlcNAc branching to the oligosaccharide attached to Asn 772 in the serine protease domain of matriptase plays a pivotal role in its stability and resistance against trypsin. Glycobiology 14(2):139-146. doi:10.1093/glycob/cwh013

37. Rambaruth ND, Dwek MV (2011) Cell surface glycan-lectin interactions in tumor metastasis. Acta Histochem 113(6): 591-600. doi:10.1016/j.acthis.2011.03.001

38. Li D, Li Y, Wu X, Li Q, Yu J, Gen J, Zhang XL (2008) Knockdown of Mgat5 inhibits breast cancer cell growth with activation of $\mathrm{CD} 4+\mathrm{T}$ cells and macrophages. J Immunol 180(5):3158-3165

39. Taniguchi N, Ihara S, Saito T, Miyoshi E, Ikeda Y, Honke K (2001) Implication of GnT-V in cancer metastasis: a glycomic approach for identification of a target protein and its unique function as an angiogenic cofactor. Glycoconj J 18(11-12):859-865

40. Anugraham M, Jacob F, Nixdorf S, Everest-Dass AV, Heinzelmann-Schwarz V, Packer NH (2014) Specific glycosylation of membrane proteins in epithelial ovarian cancer cell lines: glycan structures reflect gene expression and DNA methylation status. Mol Cell Proteomics. doi:10.1074/mcp.M113.037085

41. Zhang X, Wang Y, Qian Y, Wu X, Zhang Z, Liu X, Zhao R, Zhou L, Ruan Y, Xu J, Liu H, Ren S, Xu C, Gu J (2014) Discovery of specific metastasis-related $N$-glycan alterations in epithelial ovarian cancer based on quantitative glycomics. PLoS ONE 9(2):e87978. doi:10.1371/journal.pone.0087978

42. Miwa HE, Song Y, Alvarez R, Cummings RD, Stanley P (2012) The bisecting GlcNAc in cell growth control and tumor progression. Glycoconj J 29(8-9):609-618. doi:10.1007/s10719012-9373-6
43. Nicoll G, Avril T, Lock K, Furukawa K, Bovin N, Crocker PR (2003) Ganglioside GD3 expression on target cells can modulate NK cell cytotoxicity via siglec-7-dependent and -independent mechanisms. Eur J Immunol 33(6):1642-1648. doi:10.1002/eji. 200323693

44. Nores GA, Dohi T, Taniguchi M, Hakomori S (1987) Densitydependent recognition of cell surface GM3 by a certain antimelanoma antibody, and GM3 lactone as a possible immunogen: requirements for tumor-associated antigen and immunogen. J Immunol 139(9):3171-3176

45. Miyazaki K, Ohmori K, Izawa M, Koike T, Kumamoto K, Furukawa K, Ando T, Kiso M, Yamaji T, Hashimoto Y, Suzuki A, Yoshida A, Takeuchi M, Kannagi R (2004) Loss of disialyl Lewis(a), the ligand for lymphocyte inhibitory receptor sialic acid-binding immunoglobulin-like lectin-7 (Siglec-7) associated with increased sialyl Lewis(a) expression on human colon cancers. Cancer Res 64(13):4498-4505. doi:10.1158/0008-5472. CAN-03-3614

46. Izawa M, Kumamoto K, Mitsuoka C, Kanamori C, Kanamori A, Ohmori K, Ishida H, Nakamura S, Kurata-Miura K, Sasaki K, Nishi T, Kannagi R (2000) Expression of sialyl 6-sulfo Lewis X is inversely correlated with conventional sialyl Lewis $\mathrm{X}$ expression in human colorectal cancer. Cancer Res 60(5): $1410-1416$

47. Yusa A, Miyazaki K, Kimura N, Izawa M, Kannagi R (2010) Epigenetic silencing of the sulfate transporter gene DTDST induces sialyl Lewis ${ }^{\mathrm{x}}$ expression and accelerates proliferation of colon cancer cells. Cancer Res 70(10):4064-4073. doi:10.1158/ 0008-5472.CAN-09-2383

48. Ju T, Lanneau GS, Gautam T, Wang Y, Xia B, Stowell SR, Willard MT, Wang W, Xia JY, Zuna RE, Laszik Z, Benbrook DM, Hanigan MH, Cummings RD (2008) Human tumor antigens $\mathrm{Tn}$ and sialyl $\mathrm{Tn}$ arise from mutations in Cosmc. Cancer Res 68(6):1636-1646. doi:10.1158/0008-5472.CAN-07-2345

49. Carrascal MA, Severino PF, Guadalupe Cabral M, Silva M, Ferreira JA, Calais F, Quinto H, Pen C, Ligeiro D, Santos LL, Dall'Olio F, Videira PA (2014) Sialyl Tn-expressing bladder cancer cells induce a tolerogenic phenotype in innate and adaptive immune cells. Mol Oncol 8(3):753-765. doi:10.1016/j. molonc.2014.02.008

50. Dabelsteen E, Gao S (2005) ABO blood-group antigens in oral cancer. J Dent Res 84(1):21-28

51. Bianco T, Farmer BJ, Sage RE, Dobrovic A (2001) Loss of red cell $\mathrm{A}, \mathrm{B}$, and $\mathrm{H}$ antigens is frequent in myeloid malignancies. Blood 97(11):3633-3639

52. Büll C, Stoel MA, den Brok MH, Adema GJ (2014) Sialic acids sweeten a tumor's life. Cancer Res 74(12):3199-3204. doi:10. 1158/0008-5472.CAN-14-0728

53. Almaraz RT, Tian Y, Bhattarcharya R, Tan E, Chen SH, Dallas MR, Chen L, Zhang Z, Zhang H, Konstantopoulos K, Yarema KJ (2012) Metabolic flux increases glycoprotein sialylation: implications for cell adhesion and cancer metastasis. Mol Cell Proteomics 11(7):M112 017558. doi:10.1074/mcp.M112.017558

54. Miyagi T, Takahashi K, Hata K, Shiozaki K, Yamaguchi K (2012) Sialidase significance for cancer progression. Glycoconj J 29(8-9):567-577. doi:10.1007/s10719-012-9394-1

55. Hudak JE, Canham SM, Bertozzi CR (2014) Glycocalyx engineering reveals a Siglec-based mechanism for NK cell immunoevasion. Nat Chem Biol 10(1):69-75. doi:10.1038/ nchembio. 1388

56. Muchmore EA, Milewski M, Varki A, Diaz S (1989) Biosynthesis of $\mathrm{N}$-glycolylneuraminic acid. The primary site of hydroxylation of $N$-acetylneuraminic acid is the cytosolic sugar nucleotide pool. J Biol Chem 264(34):20216-20223

57. Shaw L, Schauer R (1988) The biosynthesis of $N$-glycoloylneuraminic acid occurs by hydroxylation of the CMP-glycoside 
of $N$-acetylneuraminic acid. Biol Chem Hoppe Seyler 369(6):477-486

58. Shaw L, Schauer R (1989) Detection of CMP- $N$-acetylneuraminic acid hydroxylase activity in fractionated mouse liver. Biochem J 263(2):355-363

59. Malykh YN, Schauer R, Shaw L (2001) N-Glycolylneuraminic acid in human tumours. Biochimie 83(7):623-634

60. Higashi H, Hirabayashi Y, Fukui Y, Naiki M, Matsumoto M, Ueda S, Kato S (1985) Characterization of $N$-glycolylneuraminic acid-containing gangliosides as tumor-associated Hanganutziu-Deicher antigen in human colon cancer. Cancer Res 45(8):3796-3802

61. Marquina G, Waki H, Fernandez LE, Kon K, Carr A, Valiente O, Perez R, Ando S (1996) Gangliosides expressed in human breast cancer. Cancer Res 56(22):5165-5171

62. Zhong Y, Wu Y, Li C, Tang J, Wang X, Ren G, Carr A, Perez R, Guo W (2012) N-Glycolyl GM3 ganglioside immunoexpression in oral mucosal melanomas of Chinese. Oral Dis 18(8):741-747. doi:10.1111/j.1601-0825.2012.01939.x

63. Higashi H, Sasabe T, Fukui Y, Maru M, Kato S (1988) Detection of gangliosides as $\mathrm{N}$-glycolylneuraminic acid-specific tumor-associated Hanganutziu-Deicher antigen in human retinoblastoma cells. Jpn J Cancer Res 79(8):952-956

64. Banda K, Gregg CJ, Chow R, Varki NM, Varki A (2012) Metabolism of vertebrate amino sugars with $N$-glycolyl groups: mechanisms underlying gastrointestinal incorporation of the non-human sialic acid xeno-autoantigen $\mathrm{N}$-glycolylneuraminic acid. J Biol Chem 287(34):28852-28864. doi:10.1074/jbc. M112.364182

65. Bardor M, Nguyen DH, Diaz S, Varki A (2005) Mechanism of uptake and incorporation of the non-human sialic acid $\mathrm{N}$-glycolylneuraminic acid into human cells. J Biol Chem 280(6):4228-4237. doi:10.1074/jbc.M412040200

66. Tangvoranuntakul P, Gagneux P, Diaz S, Bardor M, Varki N, Varki A, Muchmore E (2003) Human uptake and incorporation of an immunogenic nonhuman dietary sialic acid. Proc Natl Acad Sci USA 100(21):12045-12050. doi:10.1073/pnas. 2131556100

67. Hedlund M, Tangvoranuntakul P, Takematsu H, Long JM, Housley GD, Kozutsumi Y, Suzuki A, Wynshaw-Boris A, Ryan AF, Gallo RL, Varki N, Varki A (2007) $N$-glycolylneuraminic acid deficiency in mice: implications for human biology and evolution. Mol Cell Biol 27(12):4340-4346. doi:10.1128/MCB. 00379-07

68. Yin J, Miyazaki K, Shaner RL, Merrill AH Jr, Kannagi R (2010) Altered sphingolipid metabolism induced by tumor hypoxianew vistas in glycolipid tumor markers. FEBS Lett 584(9):1872-1878. doi:10.1016/j.febslet.2009.11.019

69. Yin J, Hashimoto A, Izawa M, Miyazaki K, Chen GY, Takematsu H, Kozutsumi Y, Suzuki A, Furuhata K, Cheng FL, Lin CH, Sato C, Kitajima K, Kannagi R (2006) Hypoxic culture induces expression of sialin, a sialic acid transporter, and cancer-associated gangliosides containing non-human sialic acid on human cancer cells. Cancer Res 66(6):2937-2945. doi:10.1158/ 0008-5472.CAN-05-2615

70. Zhu A, Hurst R (2002) Anti- $N$-glycolylneuraminic acid antibodies identified in healthy human serum. Xenotransplantation 9(6):376-381

71. Padler-Karavani V, Yu H, Cao H, Chokhawala H, Karp F, Varki N, Chen X, Varki A (2008) Diversity in specificity, abundance, and composition of anti-Neu5Gc antibodies in normal humans: potential implications for disease. Glycobiology 18(10): 818-830. doi:10.1093/glycob/cwn072

72. Padler-Karavani V, Hurtado-Ziola N, Pu M, Yu H, Huang S, Muthana S, Chokhawala HA, Cao H, Secrest P, FriedmannMorvinski D, Singer O, Ghaderi D, Verma IM, Liu YT, Messer
K, Chen X, Varki A, Schwab R (2011) Human xeno-autoantibodies against a non-human sialic acid serve as novel serum biomarkers and immunotherapeutics in cancer. Cancer Res 71(9):3352-3363. doi:10.1158/0008-5472.CAN-10-4102

73. Samraj AN, Laubli H, Varki N, Varki A (2014) Involvement of a non-human sialic Acid in human cancer. Front Oncol 4:33. doi:10.3389/fonc.2014.00033

74. Amon R, Reuven EM, Leviatan Ben-Arye S, Padler-Karavani V (2014) Glycans in immune recognition and response. Carbohydr Res 389:115-122. doi:10.1016/j.carres.2014.02.004

75. Pearce OM, Laubli H, Verhagen A, Secrest P, Zhang J, Varki NM, Crocker PR, Bui JD, Varki A (2014) Inverse hormesis of cancer growth mediated by narrow ranges of tumor-directed antibodies. Proc Natl Acad Sci USA 111(16):5998-6003. doi:10.1073/pnas.1209067111

76. Hedlund M, Padler-Karavani V, Varki NM, Varki A (2008) Evidence for a human-specific mechanism for diet and antibodymediated inflammation in carcinoma progression. Proc Natl Acad Sci USA 105(48):18936-18941. doi:10.1073/pnas. 0803943105

77. Marth JD, Grewal PK (2008) Mammalian glycosylation in immunity. Nat Rev Immunol 8(11):874-887. doi:10.1038/ nri2417

78. van Kooyk Y, Rabinovich GA (2008) Protein-glycan interactions in the control of innate and adaptive immune responses. Nat Immunol 9(6):593-601. doi:10.1038/ni.f.203

79. von Gunten S, Shoenfeld Y, Blank M, Branch DR, Vassilev T, Käsermann F, Bayry J, Kaveri S, Simon HU (2014) IVIG pluripotency and the concept of Fc-sialylation: challenges to the scientist. Nat Rev Immunol 14(5):349. doi:10.1038/ nri3401-c1

80. Varki A (2007) Glycan-based interactions involving vertebrate sialic-acid-recognizing proteins. Nature 446(7139):1023-1029. doi:10.1038/nature 05816

81. Rabinovich GA, Croci DO (2012) Regulatory circuits mediated by lectin-glycan interactions in autoimmunity and cancer. Immunity 36(3):322-335. doi:10.1016/j.immuni.2012.03.004

82. Geijtenbeek TB, Gringhuis SI (2009) Signalling through C-type lectin receptors: shaping immune responses. Nat Rev Immunol 9(7):465-479. doi:10.1038/nri2569

83. von Gunten S, Bochner BS (2008) Basic and clinical immunology of Siglecs. Ann N Y Acad Sci 1143:61-82. doi:10.1196/ annals. 1443.011

84. Zhuo Y, Bellis SL (2011) Emerging role of alpha2,6-sialic acid as a negative regulator of galectin binding and function. J Biol Chem 286(8):5935-5941. doi:10.1074/jbc.R110.191429

85. Jandus C, Boligan KF, Chijioke O, Liu H, Dahlhaus M, Demoulins T, Schneider C, Wehrli M, Hunger RE, Baerlocher GM, Simon HU, Romero P, Munz C, von Gunten S (2014) Interactions between Siglec-7/9 receptors and ligands influence NK cell-dependent tumor immunosurveillance. J Clin Invest 124(4):1810-1820. doi:10.1172/JCI65899

86. Kawasaki Y, Ito A, Withers DA, Taima T, Kakoi N, Saito S, Arai Y (2010) Ganglioside DSGb5, preferred ligand for Siglec7, inhibits NK cell cytotoxicity against renal cell carcinoma cells. Glycobiology 20(11):1373-1379. doi:10.1093/glycob/ cwq116

87. Cohen M, Elkabets M, Perlmutter M, Porgador A, Voronov E, Apte RN, Lichtenstein RG (2010) Sialylation of 3-methylcholanthrene-induced fibrosarcoma determines antitumor immune responses during immunoediting. J Immunol 185(10): 5869-5878. doi:10.4049/jimmunol.1001635

88. Tsuboi S, Sutoh M, Hatakeyama S, Hiraoka N, Habuchi T, Horikawa Y, Hashimoto Y, Yoneyama T, Mori K, Koie T, Nakamura T, Saitoh H, Yamaya K, Funyu T, Fukuda M, Ohyama C (2011) A novel strategy for evasion of NK cell immunity 
by tumours expressing core2 $O$-glycans. EMBO J 30(15): 3173-3185. doi:10.1038/emboj.2011.215

89. Kim YJ, Borsig L, Varki NM, Varki A (1998) P-selectin deficiency attenuates tumor growth and metastasis. Proc Natl Acad Sci USA 95(16):9325-9330

90. Stone JP, Wagner DD (1993) P-selectin mediates adhesion of platelets to neuroblastoma and small cell lung cancer. J Clin Invest 92(2):804-813. doi:10.1172/JCI116654

91. Garcia J, Callewaert N, Borsig L (2007) P-selectin mediates metastatic progression through binding to sulfatides on tumor cells. Glycobiology 17(2):185-196. doi:10.1093/glycob/cw1059

92. Borsig L, Wong R, Feramisco J, Nadeau DR, Varki NM, Varki A (2001) Heparin and cancer revisited: mechanistic connections involving platelets, P-selectin, carcinoma mucins, and tumor metastasis. Proc Natl Acad Sci USA 98(6):3352-3357. doi:10. 1073/pnas.061615598

93. Nieswandt B, Hafner M, Echtenacher B, Mannel DN (1999) Lysis of tumor cells by natural killer cells in mice is impeded by platelets. Cancer Res 59(6):1295-1300

94. Palumbo JS, Talmage KE, Massari JV, La Jeunesse CM, Flick MJ, Kombrinck KW, Jirouskova M, Degen JL (2005) Platelets and fibrin(ogen) increase metastatic potential by impeding natural killer cell-mediated elimination of tumor cells. Blood 105(1):178-185. doi:10.1182/blood-2004-06-2272

95. Kopp HG, Placke T, Salih HR (2009) Platelet-derived transforming growth factor-beta down-regulates NKG2D thereby inhibiting natural killer cell antitumor reactivity. Cancer Res 69(19):7775-7783. doi:10.1158/0008-5472.CAN-09-2123

96. Crespo HJ, Lau JT, Videira PA (2013) Dendritic cells: a spot on sialic acid. Front Immunol 4:491. doi:10.3389/fimmu.2013. 00491

97. Napoletano C, Rughetti A, Agervig Tarp MP, Coleman J, Bennett EP, Picco G, Sale P, Denda-Nagai K, Irimura T, Mandel U, Clausen H, Frati L, Taylor-Papadimitriou J, Burchell J, Nuti M (2007) Tumor-associated Tn-MUC1 glycoform is internalized through the macrophage galactose-type C-type lectin and delivered to the HLA class I and II compartments in dendritic cells. Cancer Res 67(17):8358-8367. doi:10.1158/0008-5472. CAN-07-1035

98. Singh SK, Streng-Ouwehand I, Litjens M, Kalay H, Saeland E, van Kooyk Y (2011) Tumour-associated glycan modifications of antigen enhance MGL2 dependent uptake and MHC class I restricted CD8 T cell responses. Int J Cancer 128(6):1371-1383. doi:10.1002/ijc. 25458

99. Nonaka M, Ma BY, Murai R, Nakamura N, Baba M, Kawasaki N, Hodohara K, Asano S, Kawasaki T (2008) Glycosylationdependent interactions of C-type lectin DC-SIGN with colorectal tumor-associated Lewis glycans impair the function and differentiation of monocyte-derived dendritic cells. J Immunol 180(5):3347-3356

100. Fedarko NS, Fohr B, Robey PG, Young MF, Fisher LW (2000) Factor $\mathrm{H}$ binding to bone sialoprotein and osteopontin enables tumor cell evasion of complement-mediated attack. J Biol Chem 275(22):16666-16672. doi:10.1074/jbc.M001123200

101. Shi WX, Chammas R, Varki NM, Powell L, Varki A (1996) Sialic acid 9-O-acetylation on murine erythroleukemia cells affects complement activation, binding to I-type lectins, and tissue homing. J Biol Chem 271(49):31526-31532

102. Ajona D, Castano Z, Garayoa M, Zudaire E, Pajares MJ, Martinez A, Cuttitta F, Montuenga LM, Pio R (2004) Expression of complement factor $\mathrm{H}$ by lung cancer cells: effects on the activation of the alternative pathway of complement. Cancer Res 64(17):6310-6318. doi:10.1158/0008-5472.CAN-03-2328

103. Crocker PR, Paulson JC, Varki A (2007) Siglecs and their roles in the immune system. Nat Rev Immunol 7(4):255-266. doi:10. 1038/nri2056
104. Crocker PR, Redelinghuys P (2008) Siglecs as positive and negative regulators of the immune system. Biochem Soc Trans 36(Pt 6):1467-1471. doi:10.1042/BST0361467

105. Jandus C, Simon HU, von Gunten S (2011) Targeting siglecs-a novel pharmacological strategy for immuno- and glycotherapy. Biochem Pharmacol 82(4):323-332. doi:10.1016/j.bcp.2011.05. 018

106. Cao H, Crocker PR (2011) Evolution of CD33-related siglecs: regulating host immune functions and escaping pathogen exploitation? Immunology 132(1):18-26. doi:10.1111/j.13652567.2010.03368.x

107. Macauley MS, Crocker PR, Paulson JC (2014) Siglec-mediated regulation of immune cell function in disease. Nat Rev Immunol 14(10):653-666. doi:10.1038/nri3737

108. von Gunten S, Simon HU (2006) Sialic acid binding immunoglobulin-like lectins may regulate innate immune responses by modulating the life span of granulocytes. FASEB J 20(6): 601-605. doi:10.1096/fj.05-5401hyp

109. Crocker PR, McMillan SJ, Richards HE (2012) CD33-related siglecs as potential modulators of inflammatory responses. Ann N Y Acad Sci 1253:102-111. doi:10.1111/j.1749-6632.2011.06449.x

110. Nutku E, Aizawa H, Hudson SA, Bochner BS (2003) Ligation of Siglec-8: a selective mechanism for induction of human eosinophil apoptosis. Blood 101(12):5014-5020. doi:10.1182/blood2002-10-3058

111. von Gunten S, Yousefi S, Seitz M, Jakob SM, Schaffner T, Seger R, Takala J, Villiger PM, Simon HU (2005) Siglec-9 transduces apoptotic and nonapoptotic death signals into neutrophils depending on the proinflammatory cytokine environment. Blood 106(4):1423-1431. doi:10.1182/blood-2004-10-4112

112. Mitsuki M, Nara K, Yamaji T, Enomoto A, Kanno M, Yamaguchi Y, Yamada A, Waguri S, Hashimoto Y (2010) Siglec-7 mediates nonapoptotic cell death independently of its immunoreceptor tyrosine-based inhibitory motifs in monocytic cell line U937. Glycobiology 20(3):395-402. doi:10.1093/glycob/ cwp195

113. von Gunten S, Jakob SM, Geering B, Takala J, Simon HU (2009) Different patterns of Siglec-9-mediated neutrophil death responses in septic shock. Shock 32(4):386-392. doi:10.1097/ SHK.0b013e3181a1bc98

114. von Gunten S, Simon HU (2007) Autophagic-like cell death in neutrophils induced by autoantibodies. Autophagy 3(1):67-68

115. von Gunten S, Schaub A, Vogel M, Stadler BM, Miescher S, Simon HU (2006) Immunologic and functional evidence for anti-Siglec-9 autoantibodies in intravenous immunoglobulin preparations. Blood 108(13):4255-4259. doi:10.1182/blood2006-05-021568

116. von Gunten S, Vogel M, Schaub A, Stadler BM, Miescher S, Crocker PR, Simon HU (2007) Intravenous immunoglobulin preparations contain anti-Siglec-8 autoantibodies. J Allergy Clin Immunol 119(4):1005-1011. doi:10.1016/j.jaci.2007.01.023

117. Schaub A, von Gunten S, Vogel M, Wymann S, Ruegsegger M, Stadler BM, Spycher M, Simon HU, Miescher S (2011) Dimeric IVIG contains natural anti-Siglec-9 autoantibodies and their anti-idiotypes. Allergy 66(8):1030-1037. doi:10.1111/j.13989995.2011.02579.x

118. von Gunten S, Simon HU (2012) Granulocyte death regulation by naturally occurring autoantibodies. Adv Exp Med Biol 750:157-172. doi:10.1007/978-1-4614-3461-0_12

119. von Gunten S, Simon HU (2010) Cell death modulation by intravenous immunoglobulin. J Clin Immunol 30(Suppl 1):S24S30. doi:10.1007/s10875-010-9411-8

120. von Gunten S, Wehrli M, Simon HU (2013) Cell death in immune thrombocytopenia: novel insights and perspectives. Semin Hematol 50(Suppl 1):S109-S115. doi:10.1053/j. seminhematol.2013.03.016 
121. Chen GY, Tang J, Zheng P, Liu Y (2009) CD24 and Siglec-10 selectively repress tissue damage-induced immune responses. Science 323(5922):1722-1725. doi:10.1126/science.1168988

122. Läubli H, Pearce OM, Schwarz F, Siddiqui SS, Deng L, Stanczak MA, Deng L, Verhagen A, Secrest P, Lusk C, Schwartz AG, Varki NM, Bui JD, Varki A (2014) Engagement of myelomonocytic Siglecs by tumor-associated ligands modulates the innate immune response to cancer. Proc Natl Acad Sci USA. doi:10.1073/pnas.1409580111

123. Miyazaki K, Sakuma K, Kawamura YI, Izawa M, Ohmori K, Mitsuki M, Yamaji T, Hashimoto Y, Suzuki A, Saito Y, Dohi T, Kannagi R (2012) Colonic epithelial cells express specific ligands for mucosal macrophage immunosuppressive receptors siglec-7 and -9. J Immunol 188(9):4690-4700. doi:10.4049/ jimmunol.1100605

124. Tomioka Y, Morimatsu M, Nishijima K, Usui T, Yamamoto S, Suyama H, Ozaki K, Ito T, Ono E (2014) A soluble form of Siglec-9 provides an antitumor benefit against mammary tumor cells expressing MUC1 in transgenic mice. Biochem Biophys Res Commun 450(1):532-537. doi:10.1016/j.bbrc.2014.06.009

125. Ohta M, Ishida A, Toda M, Akita K, Inoue M, Yamashita K, Watanabe M, Murata T, Usui T, Nakada H (2010) Immunomodulation of monocyte-derived dendritic cells through ligation of tumor-produced mucins to Siglec-9. Biochem Biophys Res Commun 402(4):663-669. doi:10.1016/j.bbrc.2010.10.079

126. Toda M, Akita K, Inoue M, Taketani S, Nakada H (2008) Downmodulation of B cell signal transduction by ligation of mucins to CD22. Biochem Biophys Res Commun 372(1):45-50. doi:10. 1016/j.bbrc.2008.04.175

127. Toda M, Hisano R, Yurugi H, Akita K, Maruyama K, Inoue M, Adachi T, Tsubata T, Nakada H (2009) Ligation of tumour-produced mucins to CD22 dramatically impairs splenic marginal zone B-cells. Biochem J 417(3):673-683. doi:10.1042/BJ20081241

128. Mitic N, Milutinovic B, Jankovic M (2012) Assessment of sialic acid diversity in cancer- and non-cancer related CA125 antigen using sialic acid-binding Ig-like lectins (Siglecs). Dis Markers 32(3):187-194. doi:10.3233/DMA-2011-0872

129. Belisle JA, Horibata S, Jennifer GA, Petrie S, Kapur A, Andre S, Gabius HJ, Rancourt C, Connor J, Paulson JC, Patankar MS (2010) Identification of Siglec-9 as the receptor for MUC16 on human NK cells, B cells, and monocytes. Mol Cancer 9:118. doi:10.1186/1476-4598-9-118

130. Sabit I, Hashimoto N, Matsumoto Y, Yamaji T, Furukawa K, Furukawa K (2013) Binding of a sialic acid-recognizing lectin Siglec-9 modulates adhesion dynamics of cancer cells via calpain-mediated protein degradation. J Biol Chem 288(49): 35417-35427. doi:10.1074/jbc.M113.513192

131. Tanida S, Akita K, Ishida A, Mori Y, Toda M, Inoue M, Ohta M, Yashiro M, Sawada T, Hirakawa K, Nakada H (2013) Binding of the sialic acid-binding lectin, Siglec-9, to the membrane mucin, MUC1, induces recruitment of beta-catenin and subsequent cell growth. J Biol Chem 288(44):31842-31852. doi:10. 1074/jbc.M113.471318

132. Aalto K, Autio A, Kiss EA, Elima K, Nymalm Y, Veres TZ, Marttila-Ichihara F, Elovaara H, Saanijoki T, Crocker PR, Maksimow M, Bligt E, Salminen TA, Salmi M, Roivainen A, Jalkanen S (2011) Siglec-9 is a novel leukocyte ligand for vascular adhesion protein-1 and can be used in PET imaging of inflammation and cancer. Blood 118(13):3725-3733. doi:10. 1182/blood-2010-09-311076

133. Kivi E, Elima K, Aalto K, Nymalm Y, Auvinen K, Koivunen E, Otto DM, Crocker PR, Salminen TA, Salmi M, Jalkanen S (2009) Human Siglec-10 can bind to vascular adhesion protein-1 and serves as its substrate. Blood 114(26):5385-5392. doi:10. 1182/blood-2009-04-219253
134. Kiwamoto T, Kawasaki N, Paulson JC, Bochner BS (2012) Siglec-8 as a drugable target to treat eosinophil and mast cellassociated conditions. Pharmacol Ther 135(3):327-336. doi:10. 1016/j.pharmthera.2012.06.005

135. O'Reilly MK, Paulson JC (2009) Siglecs as targets for therapy in immune-cell-mediated disease. Trends Pharmacol Sci 30(5):240-248. doi:10.1016/j.tips.2009.02.005

136. Chen WC, Sigal DS, Saven A, Paulson JC (2012) Targeting B lymphoma with nanoparticles bearing glycan ligands of CD22. Leuk Lymphoma 53(2):208-210. doi:10.3109/10428194.2011. 604755

137. Läubli H, Borsig L (2010) Selectins promote tumor metastasis. Semin Cancer Biol 20(3):169-177. doi:10.1016/j.semcancer. 2010.04.005

138. Girard JP, Moussion C, Forster R (2012) HEVs, lymphatics and homeostatic immune cell trafficking in lymph nodes. Nat Rev Immunol 12(11):762-773. doi:10.1038/nri3298

139. Blagoveshchenskaya AD, Norcott JP, Cutler DF (1998) Lysosomal targeting of P-selectin is mediated by a novel sequence within its cytoplasmic tail. J Biol Chem 273(5):2729-2737

140. Sanada H, Midorikawa S, Yatabe J, Yatabe MS, Katoh T, Baba T, Hashimoto S, Watanabe T (2005) Elevation of serum soluble E- and P-selectin in patients with hypertension is reversed by benidipine, a long-acting calcium channel blocker. Hypertens Res 28(11):871-878. doi:10.1291/hypres.28.871

141. Kisucka J, Chauhan AK, Zhao BQ, Patten IS, Yesilaltay A, Krieger M, Wagner DD (2009) Elevated levels of soluble P-selectin in mice alter blood-brain barrier function, exacerbate stroke, and promote atherosclerosis. Blood 113(23):6015-6022. doi:10.1182/blood-2008-10-186650

142. Ay C, Simanek R, Vormittag R, Dunkler D, Alguel G, Koder S, Kornek G, Marosi C, Wagner O, Zielinski C, Pabinger I (2008) High plasma levels of soluble P-selectin are predictive of venous thromboembolism in cancer patients: results from the Vienna Cancer and Thrombosis Study (CATS). Blood 112(7):2703-2708. doi:10.1182/blood-2008-02-142422

143. Kawashima H, Fukuda M (2012) Sulfated glycans control lymphocyte homing. Ann N Y Acad Sci 1253:112-121. doi:10. 1111/j.1749-6632.2011.06356.x

144. Krause T, Turner GA (1999) Are selectins involved in metastasis? Clin Exp Metastasis 17(3):183-192

145. Hoos A, Protsyuk D, Borsig L (2014) Metastatic growth progression caused by PSGL-1-mediated recruitment of monocytes to metastatic sites. Cancer Res 74(3):695-704. doi:10.1158/ 0008-5472.CAN-13-0946

146. Borsig L, Wong R, Hynes RO, Varki NM, Varki A (2002) Synergistic effects of L- and P-selectin in facilitating tumor metastasis can involve non-mucin ligands and implicate leukocytes as enhancers of metastasis. Proc Natl Acad Sci USA 99(4):2193-2198. doi:10.1073/pnas.261704098

147. Heidemann F, Schildt A, Schmid K, Bruns OT, Riecken K, Jung C, Ittrich H, Wicklein D, Reimer R, Fehse B, Heeren J, Luers G, Schumacher U, Heine M (2014) Selectins mediate small cell lung cancer systemic metastasis. PLoS ONE 9(4):e92327. doi:10.1371/journal.pone.0092327

148. Läubli H, Stevenson JL, Varki A, Varki NM, Borsig L (2006) L-selectin facilitation of metastasis involves temporal induction of Fut7-dependent ligands at sites of tumor cell arrest. Cancer Res 66(3):1536-1542. doi:10.1158/0008-5472.CAN-05-3121

149. Prinetti A, Aureli M, Illuzzi G, Prioni S, Nocco V, Scandroglio F, Gagliano N, Tredici G, Rodriguez-Menendez V, Chigorno V, Sonnino S (2010) GM3 synthase overexpression results in reduced cell motility and in caveolin-1 upregulation in human ovarian carcinoma cells. Glycobiology 20(1):62-77. doi:10. 1093/glycob/cwp143 
150. Prinetti A, Cao T, Illuzzi G, Prioni S, Aureli M, Gagliano N, Tredici G, Rodriguez-Menendez V, Chigorno V, Sonnino S (2011) A glycosphingolipid/caveolin-1 signaling complex inhibits motility of human ovarian carcinoma cells. J Biol Chem 286(47):40900-40910. doi:10.1074/jbc.M111.286146

151. Tringali C, Lupo B, Cirillo F, Papini N, Anastasia L, Lamorte G, Colombi P, Bresciani R, Monti E, Tettamanti G, Venerando B (2009) Silencing of membrane-associated sialidase Neu3 diminishes apoptosis resistance and triggers megakaryocytic differentiation of chronic myeloid leukemic cells K562 through the increase of ganglioside GM3. Cell Death Differ 16(1):164-174. doi:10.1038/cdd.2008.141

152. Handa K, Hakomori SI (2012) Carbohydrate to carbohydrate interaction in development process and cancer progression. Glycoconj J 29(8-9):627-637. doi:10.1007/s10719-012-9380-7

153. Potapenko M, Shurin GV, de Leon J (2007) Gangliosides as immunomodulators. Adv Exp Med Biol 601:195-203

154. Varki A, Freeze HH (2009) Glycans in acquired human diseases. In: Varki A, Cummings RD, Esko JD et al (eds) Essentials of glycobiology, 2nd edn. Cold Spring Harbor, New York

155. Casadesus AV, Fernandez-Marrero Y, Clavell M, Gomez JA, Hernandez T, Moreno E, Lopez-Requena A (2013) A shift from $N$-glycolyl- to $N$-acetyl-sialic acid in the GM3 ganglioside impairs tumor development in mouse lymphocytic leukemia cells. Glycoconj J 30(7):687-699. doi:10.1007/s10719-0139473-y

156. Gabri MR, Otero LL, Gomez DE, Alonso DF (2009) Exogenous incorporation of Neugc-rich mucin augments $N$-glycolyl sialic acid content and promotes malignant phenotype in mouse tumor cell lines. J Exp Clin Cancer Res 28:146. doi:10.1186/17569966-28-146

157. Segatori VI, Vazquez AM, Gomez DE, Gabri MR, Alonso DF (2012) Preclinical evaluation of racotumomab, an anti-idiotype monoclonal antibody to $\mathrm{N}$-glycolyl-containing gangliosides, with or without chemotherapy in a mouse model of non-small cell lung cancer. Front Oncol 2:160. doi:10.3389/fonc.2012. 00160

158. Segatori VI, Otero LL, Fernandez LE, Gomez DE, Alonso DF, Gabri MR (2012) Antitumor protection by NGcGM3/VSSP vaccine against transfected B16 mouse melanoma cells overexpressing $N$-glycolylated gangliosides. Vivo 26(4):609-617

159. Labrada M, Clavell M, Bebelagua Y, Leon J, Alonso DF, Gabri MR, Veloso RC, Verez V, Fernandez LE (2010) Direct validation of NGcGM3 ganglioside as a new target for cancer immunotherapy. Expert Opin Biol Ther 10(2):153-162. doi:10. $1517 / 14712590903443084$

160. de Leon J, Fernandez A, Clavell M, Labrada M, Bebelagua Y, Mesa C, Fernandez LE (2008) Differential influence of the tumour-specific non-human sialic acid containing GM3 ganglioside on CD4+ CD25 - effector and naturally occurring CD4+ $\mathrm{CD} 25+$ regulatory $\mathrm{T}$ cells function. Int Immunol 20(4): 591-600. doi:10.1093/intimm/dxn018

161. de Leon J, Fernandez A, Mesa C, Clavel M, Fernandez LE (2006) Role of tumour-associated $\mathrm{N}$-glycolylated variant of GM3 ganglioside in cancer progression: effect over CD4 expression on $\mathrm{T}$ cells. Cancer Immunol Immunother 55(4): 443-450. doi:10.1007/s00262-005-0041-6

162. Blanco R, Blanco D, Quintana Y, Escobar X, Rengifo CE, Osorio M, Gutierrez Z, Lamadrid J, Cedeno M, Frometa M, Carr A, Rengifo E (2013) Immunoreactivity of the 14F7 Mab raised against $\mathrm{N}$-Glycolyl GM3 ganglioside in primary lymphoid tumors and lymph node metastasis. Pathol Res Int 2013:920972. doi:10.1155/2013/920972

163. Blanco R, Rengifo E, Cedeno M, Rengifo CE, Alonso DF, Carr A (2011) Immunoreactivity of the 14F7 Mab raised against $N$ glycolyl GM3 ganglioside in epithelial malignant tumors from digestive system. ISRN Gastroenterol 2011:645641. doi:10. 5402/2011/645641

164. Blanco RQ, Cedeño M, Rengifo CE, Frómeta M, Ríos M, Rengifo E, Carr A (2013) Tissue reactivity of the 14F7 Mab raised against $\mathrm{N}$-glycolyl GM3 ganglioside in tumors of neuroectodermal, mesodermal, and epithelial origin. J Biomarkers 2013:9. doi: $10.1155 / 2013 / 602417$

165. Hayashi N, Chiba H, Kuronuma K, Go S, Hasegawa Y, Takahashi M, Gasa S, Watanabe A, Hasegawa T, Kuroki Y, Inokuchi J, Takahashi $\mathrm{H}$ (2013) Detection of $N$-glycosylated gangliosides in non-small-cell lung cancer using GMR8 monoclonal antibody. Cancer Sci 104(1):43-47. doi:10.1111/cas. 12027

166. Vazquez AM, Perez A, Hernandez AM, Macias A, Alfonso M, Bombino G, Perez R (1998) Syngeneic anti-idiotypic monoclonal antibodies to an anti-NeuGc-containing ganglioside monoclonal antibody. Hybridoma 17(6):527-534

167. Hernandez AM, Toledo D, Martinez D, Grinan T, Brito V, Macias A, Alfonso S, Rondon T, Suarez E, Vazquez AM, Perez $\mathrm{R}$ (2008) Characterization of the antibody response against NeuGcGM3 ganglioside elicited in non-small cell lung cancer patients immunized with an anti-idiotype antibody. J Immunol 181(9):6625-6634

168. Alfonso S, Valdes-Zayas A, Santiesteban ER, Flores YI, Areces F, Hernandez M, Viada C, Mendoza IC, Guerra PP, Garcia E, Ortiz RA, de la Torre AV, Cepeda M, Perez K, Chong E, Hernandez AM, Toledo D, Gonzalez Z, Mazorra Z, Crombet T, Perez R, Vazquez AM, Macias AE (2014) A randomized, multicenter, placebo-controlled clinical trial of racotumomabalum vaccine as switch maintenance therapy in advanced nonsmall-cell-lung cancer patients. Clin Cancer Res. doi:10.1158/ 1078-0432.CCR-13-1674

169. Fernandez LE, Gabri MR, Guthmann MD, Gomez RE, Gold S, Fainboim L, Gomez DE, Alonso DF (2010) NGcGM3 ganglioside: a privileged target for cancer vaccines. Clin Dev Immunol 2010:814397. doi:10.1155/2010/814397

170. Estevez F, Carr A, Solorzano L, Valiente O, Mesa C, Barroso O, Sierra GV, Fernandez LE (1999) Enhancement of the immune response to poorly immunogenic gangliosides after incorporation into very small size proteoliposomes (VSSP). Vaccine 18(1-2):190-197

171. Mulens V, de la Torre A, Marinello P, Rodriguez R, Cardoso J, Diaz R, O'Farrill M, Macias A, Viada C, Saurez G, Carr A, Crombet T, Mazorra Z, Perez R, Fernandez LE (2010) Immunogenicity and safety of a NeuGcGM3 based cancer vaccine: results from a controlled study in metastatic breast cancer patients. Hum Vaccin 6(9). doi:10.4161.hv.6.9.12571

172. Osorio M, Gracia E, Reigosa E, Hernandez J, de la Torre A, Saurez G, Perez K, Viada C, Cepeda M, Carr A, Avila Y, Rodriguez M, Fernandez LE (2012) Effect of vaccination with $N$-glycolyl GM3/VSSP vaccine by subcutaneous injection in patients with advanced cutaneous melanoma. Cancer Manag Res 4:341-345. doi:10.2147/CMAR.S22617

173. Meezan E, Wu HC, Black PH, Robbins PW (1969) Comparative studies on the carbohydrate-containing membrane components of normal and virus-transformed mouse fibroblasts. II. Separation of glycoproteins and glycopeptides by sephadex chromatography. Biochemistry 8(6):2518-2524

174. Kieber-Emmons T, Saha S, Pashov A, Monzavi-Karbassi B, Murali R (2014) Carbohydrate-mimetic peptides for pan antitumor responses. Front Immunol 5:308. doi:10.3389/fimmu. 2014.00308

175. Shirota K, Kato Y, Irimura T, Kondo H, Sugiyama Y (2001) Anti-metastatic effect of the sialyl Lewis-X analog GSC-150 on the human colon carcinoma derived cell line KM12-HX in the mouse. Biol Pharm Bull 24(3):316-319 